OPEN ACCESS

Edited by:

Vincent John Martin Noah Linus Felde,

University of Kassel, Germany

Reviewed by:

Shubin Lan,

Institute of Hydroecology (CAS),

China

Roberto De Philippis,

University of Florence, Italy

*Correspondence:

Pilar Mateo

pilar.mateo@uam.es

Specialty section This article was submitted to Microbiological Chemistry and Geomicrobiology,

a section of the journal Frontiers in Microbiology

Received: 21 December 2018 Accepted: 12 April 2019 Published: 03 May 2019

Citation: Becerra-Absalón I, Muñoz-Martín MÁ, Montejano $G$ and Mateo P (2019) Differences in the Cyanobacterial Community

Composition of Biocrusts From the Drylands of Central Mexico. Are

There Endemic Species?

Front. Microbiol. 10:937.

doi: 10.3389/fmicb.2019.00937

\section{Differences in the Cyanobacterial Community Composition of Biocrusts From the Drylands of Central Mexico. Are There Endemic Species?}

\author{
Itzel Becerra-Absalón 1,2, M. Ángeles Muñoz-Martín1, Gustavo Montejano² and \\ Pilar Mateo ${ }^{1 *}$ \\ ${ }^{1}$ Departamento de Biología, Facultad de Ciencias, Universidad Autónoma de Madrid, Madrid, Spain, ${ }^{2}$ Departamento \\ de Biología Comparada, Facultad de Ciencias, Universidad Nacional Autónoma de México, Mexico City, Mexico
}

In drylands worldwide, biocrusts, topsoil microbial communities, are prevalent, contributing to the biostabilization of soils and allowing the subsequent establishment and growth of vascular plants. In early successional biocrusts, cyanobacteria are the first dominant colonizers of bare ground, largely determining their functioning. However, there are large gaps in our knowledge of the cyanobacterial diversity in biocrusts, particularly in understudied geographic regions, such as the tropical latitudes. We analyzed the diversity of the cyanobacteria inhabiting the biocrusts of semideserts from Central Mexico in two localities belonging to the same desert system (Chihuahuan Desert) that are separated by a cordillera that crosses the center of Mexico. Morphological identification of the cyanobacteria was carried out after cultivation in parallel with the direct observation of the environmental samples and was supported by genetic characterization through analysis of the 16S rRNA gene of the isolated strains and by next-generation sequencing of the soil samples. Taxonomic assignment revealed a clear dominance of heterocystous cyanobacteria at one of the studied locations (Actopan, Hidalgo state). Although heterocystous forms were abundant at the other location (Atexcac, Puebla state), almost a third of the cyanobacterial phylotypes were represented by unicellular/colonial cyanobacteria, mostly Chroococcidiopsis spp. Only $28.4 \%$ of the phylotypes were found to be common to both soils. Most of the other taxa, however, were biocrust-type specific, and approximately $35 \%$ of the phylotypes were found to be unique to the soil they were collected in. In addition, differences in the abundances of the shared cyanobacteria between the locations were also found. These differences in the cyanobacterial distribution were supported by the distinct responses of the isolated strains representative of the sites to extreme heat and desiccation in bioassays. Some cyanobacteria with high abundance or only present at the hottest Actopan site, such as Scytonema hyalinum, Scytonema crispum, Nostoc commune, Nostoc sp., and Calothrix parietina, survived extreme heat and desiccation. 
However, Tolypothrix distorta and Chroococcidiopsis spp. were clearly sensitive to these extreme conditions in relation to their lower abundances at Actopan as opposed to Atexcac. Since novel biocrust-associated phylotypes were also found, the emergence of endemic cyanobacterial taxa is discussed.

Keywords: biological soil crusts, cyanobacteria, Illumina sequencing, drylands, endemic species

\section{INTRODUCTION}

Biological soil crusts (biocrusts) are assemblages of different organisms (principally cyanobacteria, heterotrophic bacteria, algae, fungi, lichens, and bryophytes) that develop in dryland ecosystems compromising the topsoil layer, in which soil particles are aggregated through the presence and activity of these biota, and the resulting living crust covers the surface of the ground in the interspaces between plants (Garcia-Pichel, 2002; Belnap and Lange, 2003). Cyanobacteria have been proposed to act as pioneers in the stabilization process of these soils (Garcia-Pichel and Wojciechowski, 2009), with the production of polysaccharide sheaths by some of them, that aid in the formation of often centimeter-long filament bundles, contributing to the creation of a layer of fines and further enabling secondary colonization by heterocystous cyanobacteria, with eventual colonization by lichens or mosses (Garcia-Pichel et al., 2016). Soil characteristics, mainly texture, greatly influence biocrust formation and structure since a fine texture allows motility of colonizing filaments, further increasing soil aggregation (Rozenstein et al., 2014; Chamizo et al., 2018). The physiological features of different cyanobacteria will determine the colonizing succession within a cyanobacterial biocrust community, since those populations able to cope to extreme conditions, such as desiccation, temperature extremes, and high radiation, will survive in these unfavorable environments, such as the drylands. Many of these traits are related to adaptive mechanisms, for instance, the synthesis of sunscreen pigments or dormant cells (akinetes) that allow to cope with high radiation and desiccation respectively (GarciaPichel and Castenholz, 1991; Hu et al., 2012). Evidence has shown that cyanobacteria from biocrusts play important roles in key ecosystem processes, such as their contributions to soil fertility through nitrogen fixation and carbon sequestration, their ability to stabilize soils, their response to and recovery from fire and surface disturbance, and their effects on vascular plant establishment and growth (Lange and Belnap, 2016). Nitrogenfixing cyanobacteria, free or growing in symbiosis in lichens, are the dominant $\mathrm{N}$ fixers in biocrusts (Barger et al., 2016), which exert a strong influence on the enrichment of the $\mathrm{N}$ pool in soils from low-nutrient environments.

Biocrusts are found on all continents, and studies of their distribution have expanded in North America, Asia, Africa, the Middle East, and Europe (Bowker et al., 2016 and references therein). Knowledge about cyanobacteria is rapidly increasing with the use of culture-independent sequencing studies. For instance, a continental-scale compositional survey of the cyanobacterial diversity in biocrusts of geographically distinct areas in the arid western United States revealed patterns of its abundance and distribution (Garcia-Pichel et al., 2013). Other studies showed differences in the cyanobacterial populations depending on the geographical region. In different arid and semiarid regions of warm climates, the filamentous nonheterocystous genus Microcoleus is the major component of the biocrusts (Büdel et al., 2016), while in Western Europe and Artic biocrust other filamentous non-heterocystous cyanobacteria belonging to the family of Leptolyngbyaceae were found to be dominant (Pushkareva et al., 2015; Williams et al., 2016). Less variation has been found regarding heterocystous cyanobacteria, whereby the genera Scytonema, Nostoc, and Tolypothrix have been found as dominant worldwide (Büdel et al., 2016). However, few investigations have been undertaken in temperate regions, and very little information is available from tropical latitudes (Belnap and Lange, 2003; Rivera-Aguilar et al., 2006; Büdel et al., 2009; Castillo-Monroy et al., 2011). In the central region of Mexico, there are arid and semiarid zones comprising important ecosystems, covering approximately $60 \%$ of the territory, in which biocrusts have a wide distribution that can constitute up to $70 \%$ of the drylands (Montaño and Monroy, 2000; RiveraAguilar et al., 2004). Therefore, in this work, two semidesert localities from Central Mexico were selected, one in Hidalgo state and another in Puebla state. These localities constitute the southern end of the oldest and most stable desert in Mexico, aged at approximately 50 million years old, the Chihuahua Desert. We aimed to study the differences in cyanobacterial diversity in biocrusts from these two locations, with distinct microclimatic conditions, through a polyphasic strategy in which microscopic analysis and molecular sequencing were combined with bioassays in order to identify causal factors influencing cyanobacterial species composition. This combined approach allowed us to determine the cyanobacterial diversity of biocrusts from one of many countries that is known for having extensive areas where these types of ecosystems are dominant, contributing to our understanding of the identity and distribution of these keystone microorganisms.

\section{MATERIALS AND METHODS}

\section{Sites for Collection of Biocrust Samples}

Biocrusts were collected from two semidesert localities from Central Mexico belonging to the extreme south of the Chihuahuan Desert (Rzedowski, 2006) (Figure 1). The first site was near the Actopan, Hidalgo state $\left(20^{\circ} 16^{\prime} 02.9^{\prime \prime} \mathrm{N}\right.$; $98^{\circ} 54^{\prime} 57.5^{\prime \prime} \mathrm{W}$ ) within the Mezquital Valley, and the second location was around the crater lake of San Luis Atexcac, Puebla state $\left(19^{\circ} 20^{\prime} 13^{\prime \prime} \mathrm{N} ; 97^{\circ} 21^{\prime} 19^{\prime \prime} \mathrm{W}\right)$ (Figure 2). Basaltic volcanic flows and mountains (Figure 2A) separate the two sites which are located in tropical latitudes. However, due to the altitude 


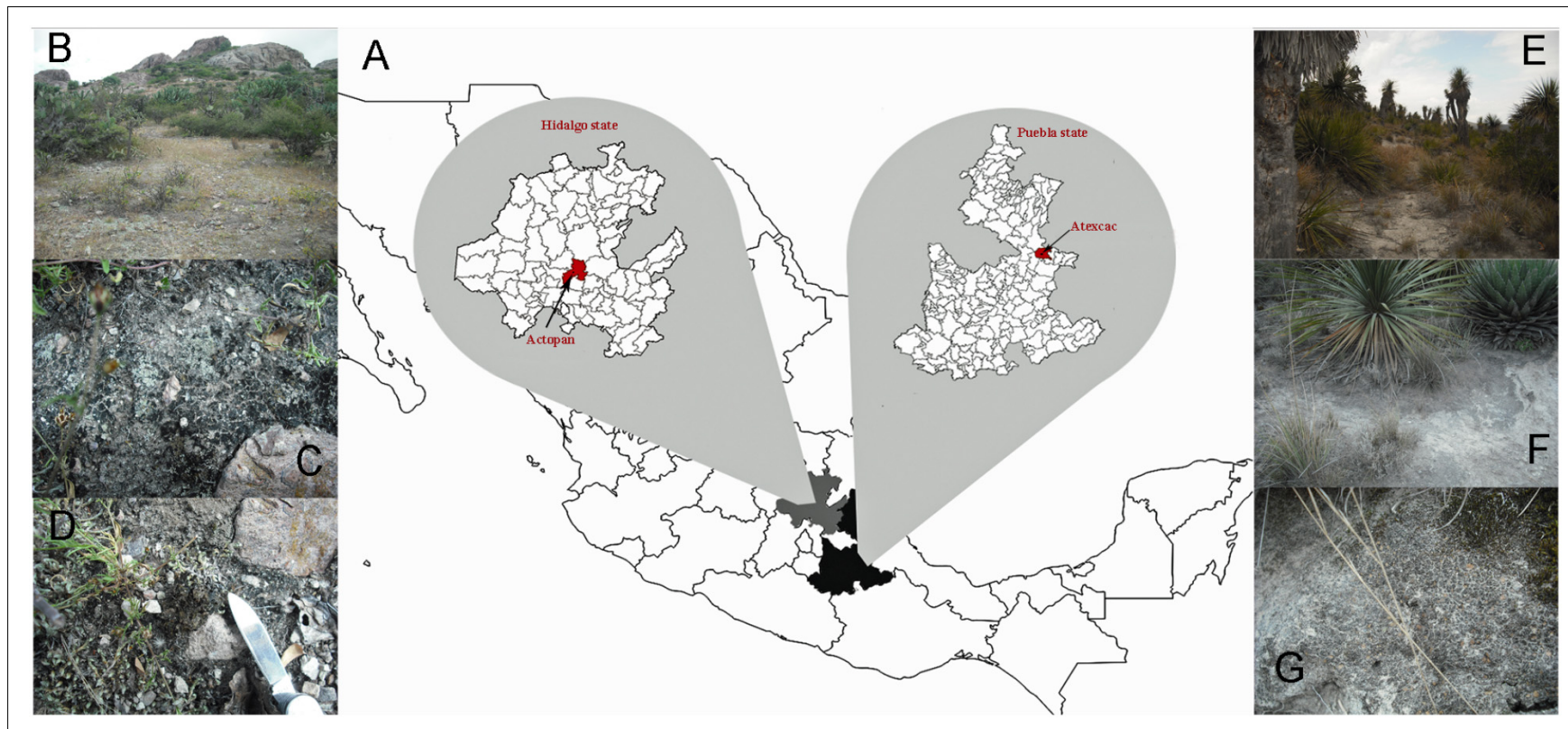

FIGURE 1 | (A) Location of sampling sites, (B) general view of Actopan locality in Hidalgo state, (C,D) biocrusts from Actopan, (E) general view of Atexcac locality in Guadalupe Victoria, Puebla state, $\mathbf{( F , G ) ~ b i o c r u s t s ~ f r o m ~ A t e x c a c . ~}$

at which they are located, more than 2,000 m.a.s.l., they are considered temperate zones. The rainfall regime is different from that of the tropical latitude due to the development of orographic rain shadows (Rzedowski, 1978) so the climate is semiarid (Figures 2B,C). There are two main seasons, a warmer one, from May to October and a cooler one, during the rest of the year. In the warmest month (May), the mean monthly temperature in Actopan was $19.1^{\circ} \mathrm{C}$ (average data from 1981 to 2010), and the minimum and maximum average temperatures ranged from 9.5 to $28.7^{\circ} \mathrm{C}$; while in Atexcac, this was $17.0^{\circ} \mathrm{C}$, and ranged from 7.7 to $26.3^{\circ} \mathrm{C}$. In the coldest months (January and December) the mean monthly temperature in Actopan was $12.4^{\circ} \mathrm{C}$ and ranged from 2.5 to $22.2^{\circ} \mathrm{C}$, while in Atexcac this was $11.2^{\circ} \mathrm{C}$ and ranged from 1.3 to $21.1^{\circ} \mathrm{C}$. The rainfall mainly occurs in the warmer season, normally in June and September. The Actopan location presented a mean annual temperature (MAT) of $16.4^{\circ} \mathrm{C}$, the minimum and maximum mean annual temperatures were $7.8^{\circ} \mathrm{C}$ and $25.1^{\circ} \mathrm{C}$, respectively, and the minimum and maximum temperatures recorded on the coldest and warmest days were $-7^{\circ} \mathrm{C}$ and $47^{\circ} \mathrm{C}$, respectively. The mean annual precipitation (MAP) was $436 \mathrm{~mm}$, and the precipitation ranged from 400 to $900 \mathrm{~mm}$. The soil type was a Phaeozem (Mollisol), fine-textured, with both alluvial and andesita deposits, and the vegetation was xerophytic crassicaule shrubs (Mesquite shrubs and trees), dominated by Prosopsis spp. with crassicaule (fleshy stemmed) plants. The Atexcac location had an MAT of $13.9^{\circ} \mathrm{C}$, the minimum and maximum annual temperatures were $5.5^{\circ} \mathrm{C}$ and $22.4^{\circ} \mathrm{C}$, respectively, and the minimum and maximum temperatures recorded on the coldest and warmest days were $-12^{\circ} \mathrm{C}$ and $36^{\circ} \mathrm{C}$, respectively. The MAP was 372 $\mathrm{mm}$, with a precipitation range of $400-900 \mathrm{~mm}$. The soil type was Phaeozem calcareous, fine-textured, and the vegetation was xerophytic shrubs with Izotal, dominated by Yucca and other Agavoideae (Alcocer et al., 2004). Another important climatic difference between the sites was the insolation; in Actopan, the location receives greater insolation all year round than does Atexcac (Figures 2G,H). The environmental data were obtained from government databases at Servicio Metereológico Nacional (SMN ${ }^{1}$, accessed March 10, 2017), Instituto Nacional de Estadistica y Geografía (INEGI ${ }^{2}$, accessed March 10, 2017), and Geoportal de la Comisión Nacional para el Conocimiento y Uso de la Biodiversidad (Conabio ${ }^{3}$, accessed March 10, 2017) and had been recorded over many years of monitoring (19512019). Daily climatic data of the SMN were obtained through the CICESE web platform ${ }^{4}$.

\section{Biocrust Sampling}

Biocrust samples were collected in October (Actopan), and December (Atexcac) 2014 following the procedure previously described (Garcia-Pichel et al., 2013; Muñoz-Martín et al., 2019): Nine biocrust samples were taken in each site, within an area of $25-50 \mathrm{~m}^{2}$ that was inspected to choose places that had developed biocrusts. A preliminary determination of the major cyanobacterial morphotypes and their relative abundance was carried out by direct microscopy of wetted samples. Then, representative subsamples, according to microscopic inspection, and with equal size, were selected, mixed together and homogenized with a mortar and pestle, to form a composite sample. These multiple samples, integrated field patchiness of

\footnotetext{
${ }^{1}$ http://smn.cna.gob.mx/es/

${ }^{2}$ https://www.inegi.org.mx/

${ }^{3}$ http://www.conabio.gob.mx/informacion/gis/

${ }^{4}$ http://clicom-mex.cicese.mx
} 


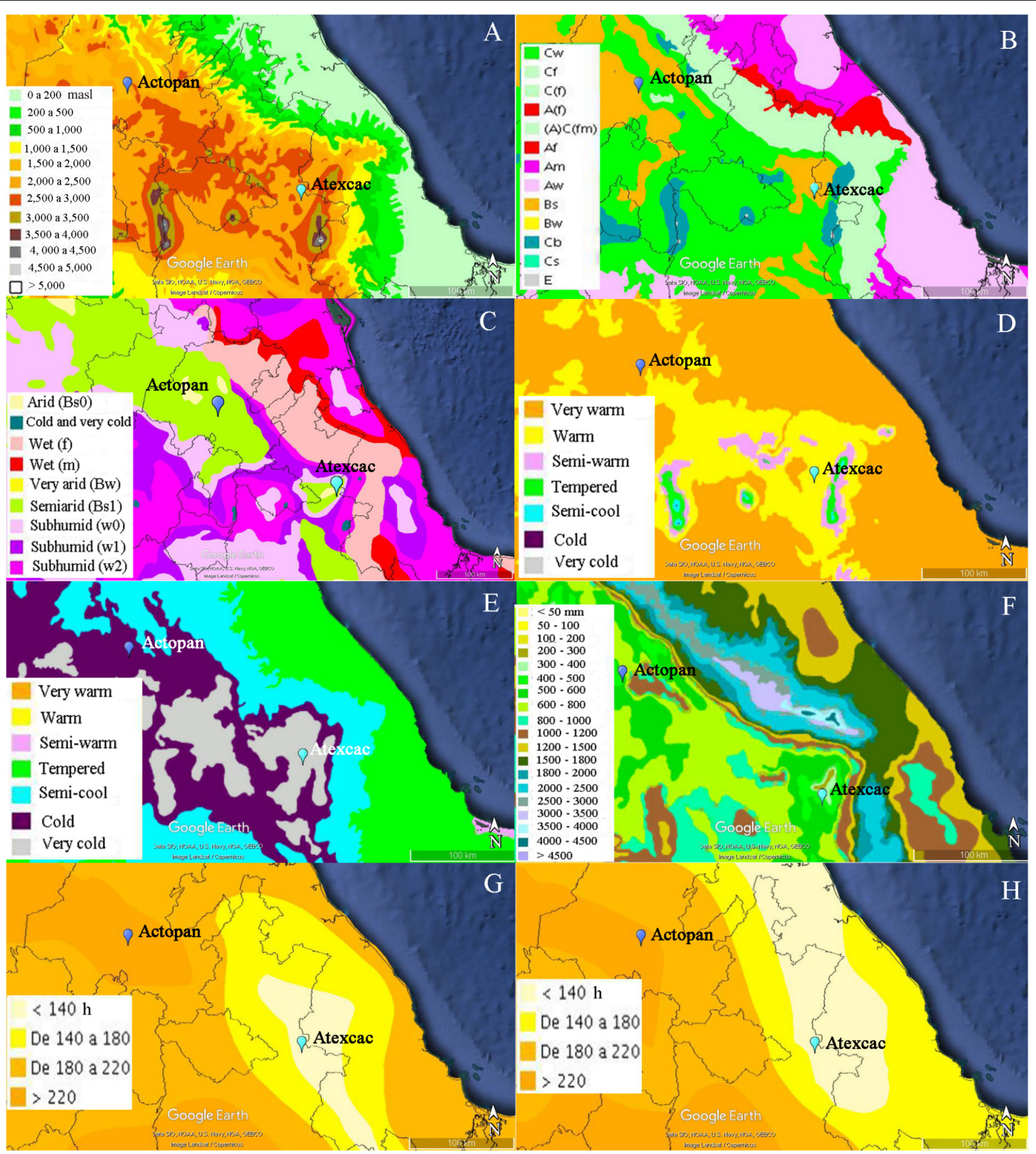

FIGURE 2 | Hypsometry and climatic characteristics of the two sampling sites: (A) hypsometry, (B) climate, (C) humidity, (D) maximum mean annual temperature, (E) minimum mean annual temperature, (F) mean annual precipitation, (G) hours of insolation during the month of maximum insolation (May), (H) hours of insolation during the month of minimum insolation (January). The climatic and geological data were obtained from the Geoportal of the National Commission for the Knowledge and Use of Biodiversity (CONABIO) in KML format and then imported into Google Earth (based on Image Landsat/Copernicus-Data SIO, NOAA, U.S. Navy, NGA, GEBCO) where the sites were located by means of the coordinates obtained with a GPS. masl, meters above sea level; Cw, temperate subhumid with dry winter; Cf, temperate humid; $C(f)$, temperate without dry season; $A(f)$, hot humid; $(A) C(f m)$, semi-hot humid; Af, hot humid; Am, hot with summer precipitations; Aw, wet; Bs, semi-arid steppe; Bw, arid desert; Cb, temperate warm summer; Cs, temperate, dry summer; E, polar.

the communities (Pushkareva et al., 2015; Muñoz-Martín et al., 2019). The samples were collected using $60 \mathrm{~mm}$ Petri dishes, of which the plate bottom was inserted into the surface to excise a circular portion of the biocrust, collecting approximately $1 \mathrm{~cm}$ deep soil without disturbing the upper layer. After collection, the samples were stored in the dark at room temperature until use. 


\section{Strains Isolation and Culture Conditions}

The dry biocrusts were reactivated by the addition of distilled water before their use for the isolation of strains. We isolated the strains by two methods: one by micromanipulation of the samples under the dissecting microscope with watchmaker's forceps, in which we manually isolated bundles of filaments as previously described (Garcia-Pichel et al., 2013) as well as filaments of heterocystous cyanobacteria. Seven strains were isolated by this procedure (see Table 1). The isolated bundles or filaments were then inoculated in multiwell plates with liquid BG11 (for non-heterocystous cyanobacteria) or BG11 medium (for heterocystous cyanobacteria) (Rippka et al., 1979).

TABLE 1 | Cyanobacterial strains isolated in this study.

\begin{tabular}{|c|c|c|c|}
\hline Taxon & $\begin{array}{l}\text { Strain number/culture } \\
\text { collection no. }\end{array}$ & $\begin{array}{l}\text { Sampling } \\
\text { site }\end{array}$ & Figure \\
\hline Nostoc commune & ACT709/UAM422 & Actopan & Figure $3 \mathrm{~A}$ \\
\hline Nostoc sp.1 & ACT703/UAM857 & Actopan & Figure 3B \\
\hline Nostoc sp.2 & ACT732/UAM446 & Actopan & Figure $3 C$ \\
\hline \multirow[t]{3}{*}{ Tolypothrix distorta } & ACT712/UAM443 & Actopan & Figure $3 \mathrm{E}$ \\
\hline & ATE705/UAM438 & Atexcac & Figure 3D \\
\hline & ATE717/UAM454 & Atexcac & \\
\hline Scytonema crispum & ACT685/UAM437* & Actopan & Figure 3F \\
\hline \multirow[t]{2}{*}{ Calothrix parietina } & ACT696/UAM439 & Actopan & Figure $3 G$ \\
\hline & ACT713/UAM858 & Actopan & \\
\hline \multirow[t]{9}{*}{ Scytonema hyalinum } & ACT694/UAM441 & Actopan & \\
\hline & ACT695/UAM447 & Actopan & \\
\hline & ATE698/UAM456 & Atexcac & \\
\hline & ACT699/UAM440* & Actopan & Figure $3 \mathbf{H}$ \\
\hline & ACT700/UAM436 & Actopan & \\
\hline & ATE704/UAM455* & Atexcac & Figure 3I \\
\hline & ACT706/UAM859* & Actopan & \\
\hline & ACT711/UAM448* & Actopan & \\
\hline & ATE714/UAM860 & Atexcac & \\
\hline Chroococcidiopsis sp.1 & ATE715/UAM434 & Atexcac & Figure $3 \mathbf{J}$ \\
\hline Chroococcidiopsis sp.2 & ATE707/UAM433 & Atexcac & Figure $3 \mathrm{~K}$ \\
\hline Kamptonema sp. & ACT692/UAM457 & Actopan & Figure $3 \mathrm{M}$ \\
\hline Microcoleus vaginatus & ACT688/UAM445* & Actopan & Figure $3 \mathrm{~N}$ \\
\hline Porphyrosiphon notarisii & АCT693/UAM430* & Actopan & Figure 30 \\
\hline Oculatella atacamensis & ATE710/UAM427 & Atexcac & Figure 3P \\
\hline Oculatella sp. & ACT687/UAM426 & Actopan & Figure 3V \\
\hline Leptolyngbya sp. & ACT691/UAM424 & Actopan & Figure $3 \mathbf{T}$ \\
\hline Leptolyngbya sp. & ACT689/UAM432 & Actopan & Figure $3 U$ \\
\hline Leptolyngbya frigida & ACT684/UAM425 & Actopan & Figure $3 Q$ \\
\hline Schizothrix sp. & ACT690/UAM431 & Actopan & Figures 3R,S \\
\hline \multirow[t]{4}{*}{ Chroakolemma opaca } & ACT686/UAM423 & Actopan & \\
\hline & ACT701/UAM861 & Actopan & Figure $3 W$ \\
\hline & ACT702/UAM862 & Actopan & \\
\hline & ACT708/UAM863 & Actopan & \\
\hline \multirow[t]{3}{*}{ Chroakolemma pellucida } & ATE716/UAM429 & Atexcac & \\
\hline & ATE718/UAM428 & Atexcac & \\
\hline & ATE719/UAM864 & Atexcac & Figure $3 \mathrm{X}$ \\
\hline Synechococcus sp. & ATE729/UAM435 & Atexcac & Figure 3L \\
\hline
\end{tabular}

*Strains isolated by micromanipulation (see "Materials and Methods" section).
Cycloheximide $\left(0.1 \mathrm{mg} \mathrm{mL}^{-1}\right)$ was also added to avoid fungal contamination. In a second, parallel method, the topsoil samples were ground with a mortar, and $0.1 \mathrm{~g}$ was mixed with $1.5 \mathrm{~mL}$ of cyanobacterial culture media and inoculated into Petri dishes ( $1.5 \%$ agar, with cycloheximide $0.1 \mathrm{mg} \mathrm{mL}^{-1}$ ) with BG11 or BG1 $11_{0}$ media. The samples were incubated in a growth chamber at $28^{\circ} \mathrm{C}, 20-50 \mu \mathrm{mol}$ photon $\mathrm{m}^{-2} \mathrm{~s}^{-1}$ and allowed to grow for approximately 4 weeks. Each strain was isolated from the colonies by selecting single trichomes or groups of cells for unicellular cyanobacteria using pulled capillary pipettes or forceps under a dissecting microscope (Leica, Leica Microsystems, Wetzler, Germany). The isolated strains were transferred to multiwell plates with liquid BG11 or BG11 $1_{0}$ and maintained under $28^{\circ} \mathrm{C}$, 20-50 $\mu$ mol photon $\mathrm{m}^{-2} \mathrm{~s}^{-1}$.

\section{Morphological Characterization}

The isolated cultured strains and cyanobacterial populations in the environmental samples were analyzed for general morphological and morphometric characteristics as previously described (Becerra-Absalon et al., 2018). The characteristics of our cyanobacteria were compared with the information provided in the taxonomic keys of Komárek and Anagnostidis $(1999,2005)$ and Komárek (2013).

\section{Isolation of Genomic DNA and Amplification of the 16S rRNA Gene of the Isolated Strains and an Environmental Sample}

Total genomic DNA extraction of the isolated cultures and an environmental sample of a macroscopic colony of Nostoc was accomplished using the Ultraclean ${ }^{\circledR}$ Microbial DNA Isolation Kit (Mo Bio Laboratories, Inc., Carlsbad, CA, United States) with a modification previously described (Loza et al., 2013) to break the exopolysaccharides surrounding many of the cyanobacterial cells. This involved a three-cycle step that consisted of freezing $0.3 \mathrm{~mL}$ aliquots of cyanobacterial suspensions of each culture in liquid nitrogen, breaking them down with an adapted drill and melting them in a $60^{\circ} \mathrm{C}$ water bath.

The 16S rRNA gene was amplified by PCR using primer 27 as the forward primer (Wilmotte et al., 1993) and primer B23SR as the reverse (Lepère et al., 2000) under conditions previously described by Mateo et al. (2011) and following the PCR conditions of Gkelis et al. (2005). This reaction produced amplification fragments of approximately 2,000 bp that span the $16 \mathrm{~S}$ rRNA gene and the intergenic region between the $16 \mathrm{~S}$ and $23 \mathrm{~S}$ rRNA genes. An agarose gel (1\%) with a $1 \mathrm{~kb}$ gene ruler (MBL Biotools, Spain) and the fluorescent DNA stain Gel $\operatorname{Red}^{\mathrm{TM}}$ were employed to check if the amplification fragments had the correct size. The DNA was purified using Wizard SV Gel and PCR Clean-Up (Promega, Madison, WI, United States) and cloned into pGEM ${ }^{\circledR}$ - T Easy Vector Systems (Promega, Madison, WI, United States). The DNA from the colonies of recombinant clones carrying the correct-sized inserts was extracted using the Wizard Miniprep Kit (Promega). The sequencing of both strands was carried out at the Genomics Core Unit of the Spanish National Cancer Research Center, Spain. Several clones from 
various strains were sequenced, obtaining a total of 46 nucleotide sequences which were deposited in the GenBank Database under the accession numbers: MK247967-MK248010 (isolated strains) and MK239479-MK239480 (environmental sample).

\section{Phylogenetic Analyses of Sequence Data}

The 16S rRNA gene sequences of approximately 1,500 bp were aligned and manually corrected using PhyDE-1 v0.9971 (Müller et al., 2010). A BLAST search (Altschul et al., 1990) was performed, and assignations with an identity value higher than 97.5\% and other representative soil cyanobacteria sequences were downloaded from the NCBI database ${ }^{5}$. Multiple alignments of all these sequences, using Gloeobacter violaceus or Chroococcidiopsis spp. sequences as outgroups, were accomplished using the function ClustalW multiple alignment, and the alignment was later visually checked and corrected using PhyDE-1 v0.9971 (Müller et al., 2010). The phylogenetic trees were computed with MEGA version 7.0.21 (Kumar et al., 2016) using neighbor-joining (NJ), maximum parsimony (MP) and maximum likelihood (ML) algorithms. For NJ, the evolutionary distances were calculated by applying the Kimura 2-parameter, gamma distributed and invariant sites with a pairwise deletion of gaps and missing data. The distances for the ML tree were estimated by the Kimura 2-parameter, gamma distributed and invariant sites, assuming a gamma distribution with four categories with the nearestneighbor-interchange. The MP tree was built with the subtreepruning-regrafting search method with 10 initial trees and 3 search levels. The gaps and missing data were treated with the complete deletion option. The standard error in all analyses was estimated with the bootstrap phylogeny test (Felsenstein, 1985) using 1,000 replications. The percentage of similarity between sequences was determined as (1-p-distance) $)^{*} 100$.

\section{Analyses of Cyanobacterial Community Composition by Amplicon Metagenomics}

Amplicon metagenomics targeted to the 16S rRNA gene and Illumina MiSeq sequencing data were used to assess the diversity and community composition of the bacteria. One gram from each composite soil sample was aliquoted into four parts $(0.25 \mathrm{~g})$ for DNA extraction using a PowerSoil DNA extraction Kit (Mo Bio, Carlsbad, CA, United States), according to the manufacturer's instructions. Because many cells were difficult to lyse, an additional step was added at the beginning of the protocol as described in Muñoz-Martín et al. (2019): the soil was incubated with the homogenization solution and exposed to three freeze-thaw cycles, alternating immersion in liquid nitrogen, heating to $60^{\circ} \mathrm{C}$, and homogenizing with a pellet pestle in an Eppendorf tube using a hand-operated homogenizer (Bosch, CSB-850-2RET). The DNA was eluted in $100 \mu \mathrm{L}$ of buffer, and the four independent DNA extractions per sample were mixed for PCR amplifications. The V4 variable region from the $16 \mathrm{~S}$ rRNA gene was amplified by PCR using the universal bacterial primers F515 and R806 as previously described by Caporaso et al. (2011) at the Microbiome Analysis Laboratory, Swette Center for Environmental Biotechnology, Biodesign Institute of

${ }^{5}$ http://www.ncbi.nlm.nih.gov/blast the Arizona State University (United States). The amplicons were processed using a MiSeq sequencer (Illumina) with a read length of $2 \times 150 \mathrm{bp}$. At least 100,000 sequences were obtained for each amplicon. Quality control checks were performed on the raw sequence data using FastQC v 0.11.3. The sequence data were processed using QIIME v 1.9.0 (Caporaso et al., 2010) and the workflow described by Pylro et al. (2014), available on http://www.brmicrobiome.org/, based on UPARSE pipeline (Edgar, 2013) implemented by the software USEARCH v. 8.1, as described in detail by Muñoz-Martín et al. (2019). A similarity cut-off value of $97 \%$ was used to cluster the operational taxonomic units (OTUs). The OTU representative sequences were taxonomically assigned against the Greengenes database (13-08) (McDonald et al., 2011) first, using the RDP classifier method with a confidence value of 0.8 (Navas-Molina et al., 2013) to define the bacterial community composition at the phylum level. For more accurate taxonomic assignation of the cyanobacterial community, an approach similar to that described in Muñoz-Martín et al. (2019) was followed. First, the representative OTU sequences were matched against the $16 \mathrm{~S}$ rDNA sequence database of the cultures obtained in this study, sequences from other cultures obtained by us from other biocrusts and other OTUs obtained in the abovementioned paper using the "uparse ref command" in USEARCH with the default parameters (Edgar, 2010). Then, all this information was compared with the taxonomic assignments made against the Greengenes database (McDonald et al., 2011) as mentioned above, and also against the SilvaMod database (Yilmaz et al., 2014) using the lowest common ancestor (LCA) algorithm implemented in CREST (Lanzen et al., 2012). In addition, the OTU representative sequences were Blasted against NCBI database. These steps allowed us to taxonomically assign almost all of the OTUs with a relative abundance of more than $0.1 \%$ in any of the locations. Alpha diversity indices (Chaol estimator, Good's coverage and observed OTUs) were calculated using QIIME. Good's coverage estimates ranged from 99.73 to $99.80 \%$, indicating that the large majority of the cyanobacterial diversity was captured. The OTU sequences have been deposited in the GenBank under accession numbers MK247058-MK247141. Raw sequencing data have been deposited in the NCBI Sequencing Read Archive under accession number PRJNA507723.

\section{Cyanobacterial Survival Bioassays}

To determine survival at high temperature and desiccation, a set of experiments was carried out with 23 of the isolated strains (see Table 4 in the results). The survival was tested by two ways: the resistance (the ability of the cyanobacteria to withstand the extreme conditions), and the resilience (the ability of the cyanobacteria to recover following the extreme conditions). Therefore, first, bioassays were carried out at $40^{\circ} \mathrm{C}$ in liquid BG11 or BG11 $1_{0}$ (for non-heterocystous and heterocystous cyanobacteria, respectively) (Rippka et al., 1979) with equal amounts of inoculum from each of the strain, in duplicate; strains were distributed in wells of sterile polystyrene 6-well microtiter plates (IWAKI Microplate). They were incubated for 25 days in a 16:8 h light:dark period with an irradiance of $30 \mu$ mol photon $\mathrm{m}^{-2} \mathrm{~s}^{-1}$. After this period of time, the cultures were left in these 
conditions until total desiccation and maintained thereafter for a year. To test the resilience following these conditions, culture medium was added to the desiccated strains and then the samples were maintained at room temperature $\left(22-24^{\circ} \mathrm{C}\right)$. The retention or total loss of pigmentation was tested for these bioassays, using the retention of chlorophyll a as a proxy of the survival, as previously described (Garcia-Pichel et al., 2013; Zhou et al., 2016).

\section{RESULTS}

\section{Morphological and Molecular (16S rRNA Gene) Analysis of Cultures: Polyphasic Identification of Isolated Strains}

A total of 37 strains were isolated from the biocrust samples and cultured (Table 1); these strains were phenotypically and phylogenetically characterized (Figures 3,4 ). In addition, an environmental sample of a macroscopic colony of Nostoc found at the Actopan sampling site and was also characterized to compare with the Nostoc isolated strains (see below). The combined morphological and genetic evaluation allowed us taxonomic identification of 21 cyanobacterial species (Table 1), in which, strains corresponding to the same species showed similar morphological characteristics (data not shown). Eighteen of the strains belonged to the heterocystous cyanobacteria (Figures 3A-I, 4A), and 19 were non-heterocystous, of which most were filamentous (16 strains), while only three strains belonged to unicellular/colonial cyanobacteria (Figures 3J-X, 4B). Nine clusters were identified in the phylogenetic tree of the heterocystous cyanobacteria (Figure 4A) and corresponded to the morphotypes found (Figures 3A-I). The Nostoc isolates fell into three different clusters (cluster I, III, and VII) according to their distinct morphological characteristics
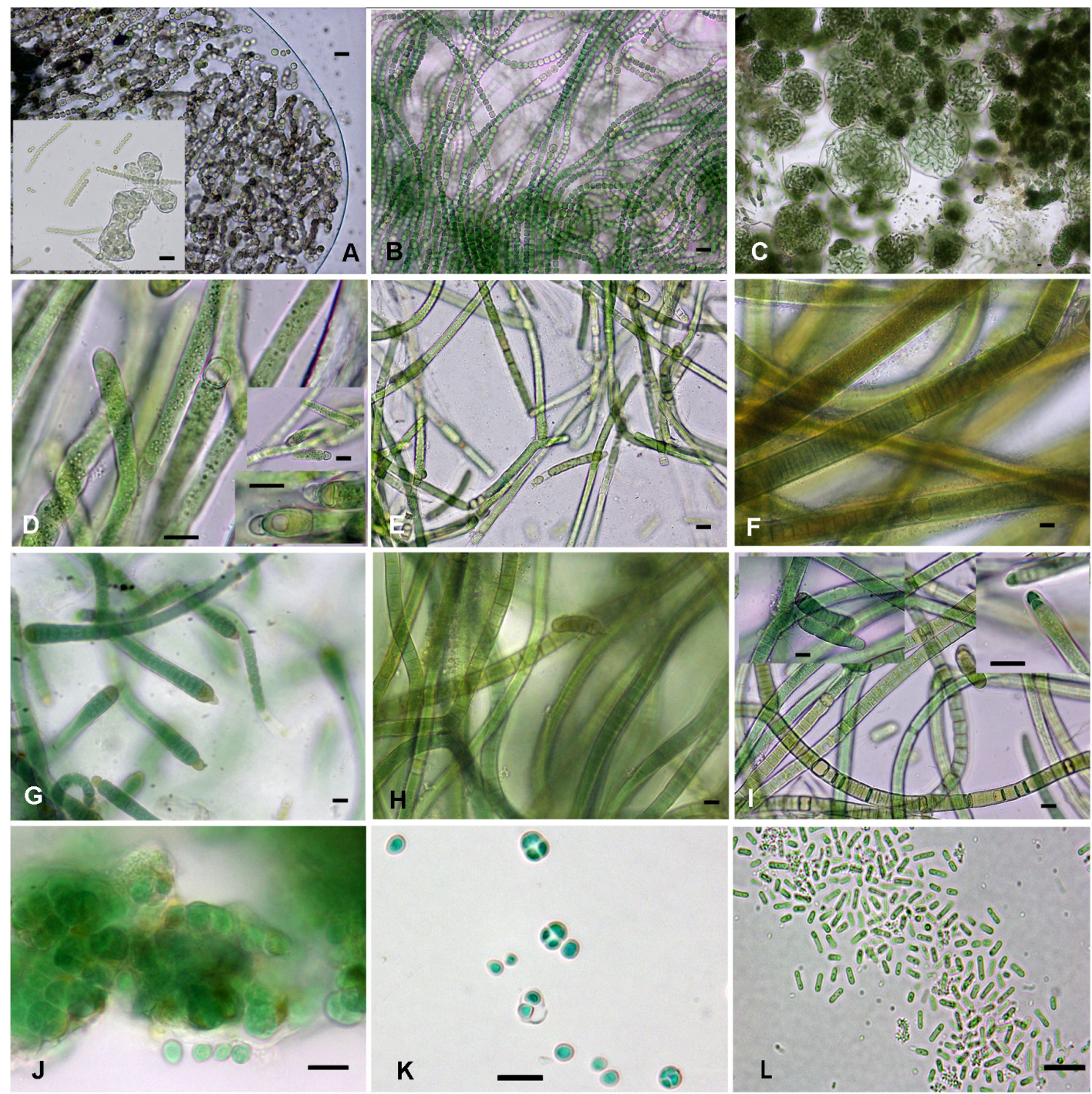

FIGURE 3 | Continued 

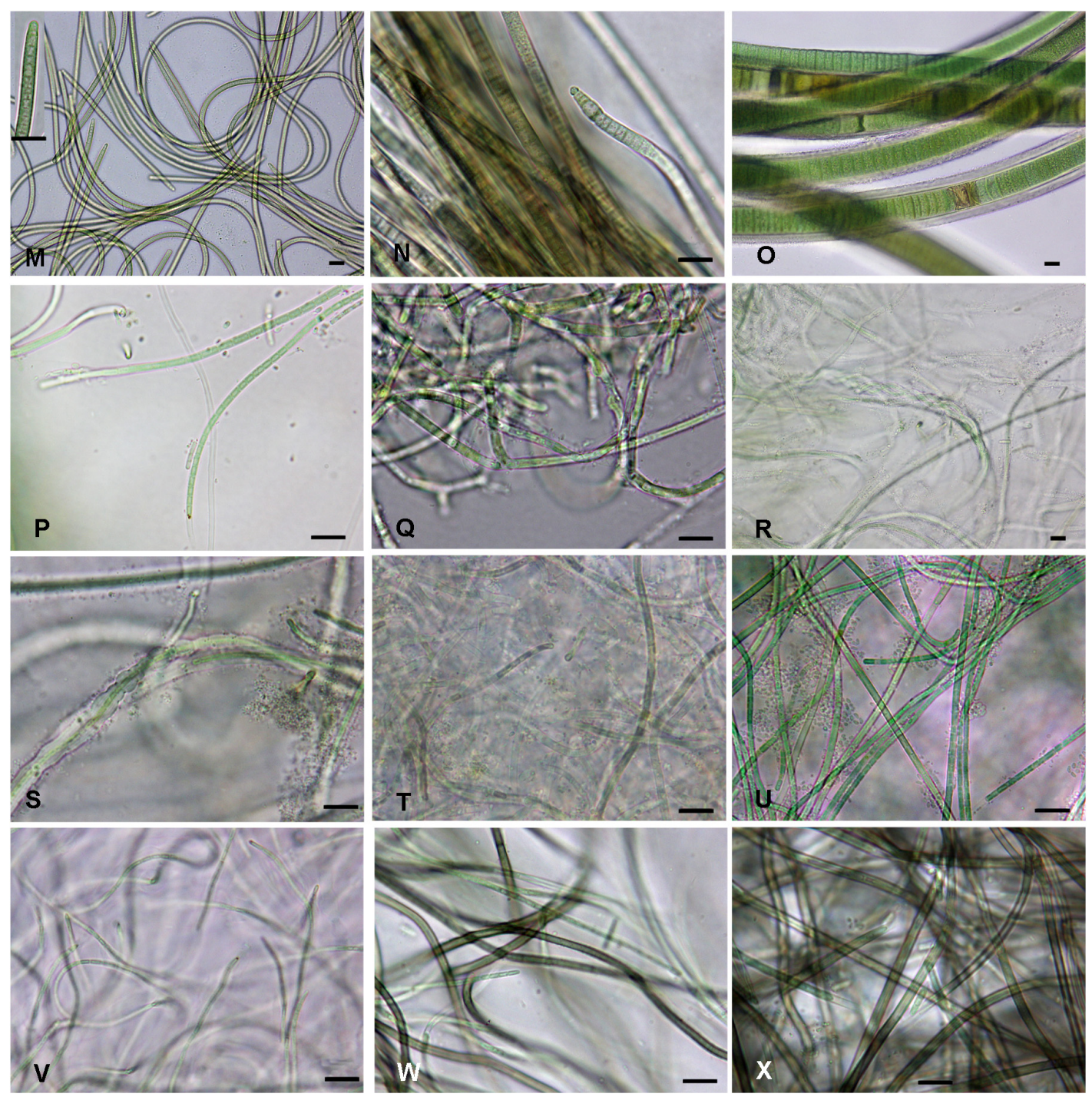

FIGURE 3 | Cyanobacterial isolated strains: (A) Nostoc commune ACT709, (B) Nostoc sp. 1 ACT703, (C) Nostoc sp. 2 ACT732, (D) Tolypothrix distorta ATE705, (E) Tolypothrix distorta ACT712, (F) Scytonema crispum ACT685, (G) Calothrix parietina ACT696, (H) Scytonema hyalinum ACT699, (I) Scytonema hyalinum ATE704, (J) Chroococcidiopsis sp.1 ATE715, (K) Chroococcidiopsis sp.2 ATE707, (L) Synechococcus sp. ATE729, (M) Kamptonema sp. ACT692, (N) Microcoleus vaginatus ACT688, (0) Porphyrosiphon notarisii ACT693, (P) Oculatella atacamensis ATE710, (Q) Leptolyngbya frigida ACT684, (R,S) Schizothrix sp. ACT690, (T) Leptolyngbya sp.1 ACT691, (U) Leptolyngbya sp.2 ACT689, (V) Oculatella sp. ACT687, (W) Chroakolemma opaca ACT701, (X) Chroakolemma pellucida ATE 719. Scale bar: $10 \mu \mathrm{m}$.

(Figures 3A-C). The 16S rRNA gene sequence from the $N$. commune isolate was placed in a cluster gathering of known representatives of $N$. commune from soils (cluster I). However, the sequences corresponding to the other isolated strains of the genus Nostoc (Nostoc sp. ACT732 and Nostoc sp. ACT703) were located in separate clusters, each of which included representatives of this genus, but with no clear specific identification (clusters III and VII, respectively). All the Nostoc phylotypes from the isolated strains were separated from those in cluster II, which included the sequence of the environmental sample fitting the morphological characteristics of Nostoc indistinguendum as well as other representatives of this taxon (cluster II). The well-supported group (cluster IV) corresponding to Tolypothrix/Spirirestis included our three isolates of Tolypothrix distorta, which showed typical characteristics of this genus, such as single falsely branched filaments originating below intercalary heterocysts (Figures 3D,E). Similarly, the morphological characteristics of the strain fitting the descriptions of Scytonema crispum (Figure 3F) were supported by its inclusion in a cluster together with other sequences of this taxon from the database (cluster V). Two isolates corresponding to Calothrix grouped with other Calothrix sequences from the databases corresponding to C. parietina (cluster VI); in addition, the morphological characteristics of these two isolates fit with 


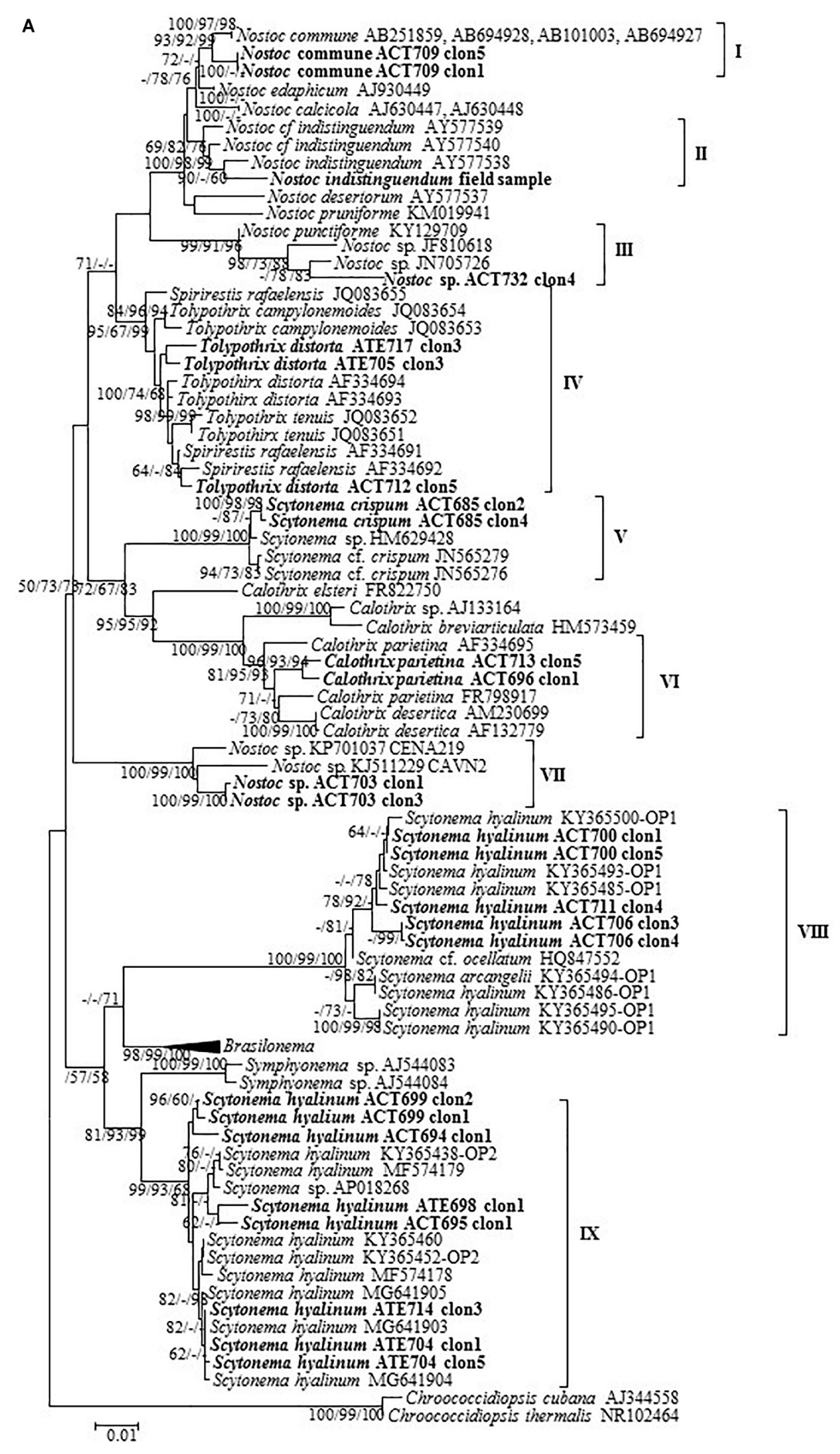

FIGURE 4 | Continued 


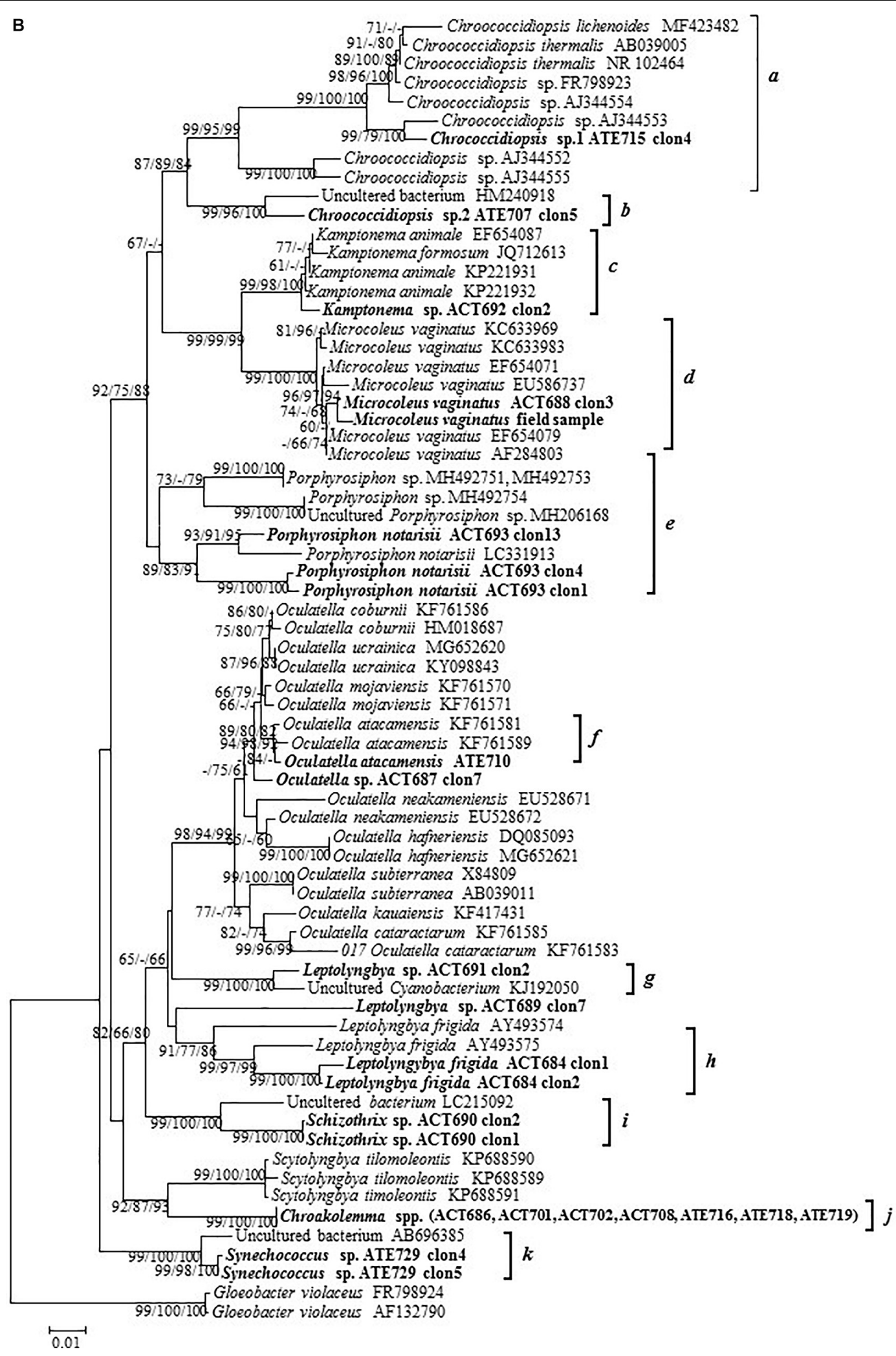

FIGURE 4 | Phylogenetic trees obtained by the neighbor-joining method representing (A) heterocystous cyanobacteria and (B) unicellular and filamentous non-heterocystous cyanobacteria, based on the analysis of the 16S rRNA gene, showing the position of the sequences obtained from the present study (in bold). Numbers near nodes indicate bootstrap values greater than or equal to $60 \%$ for NJ, ML, and MP. 

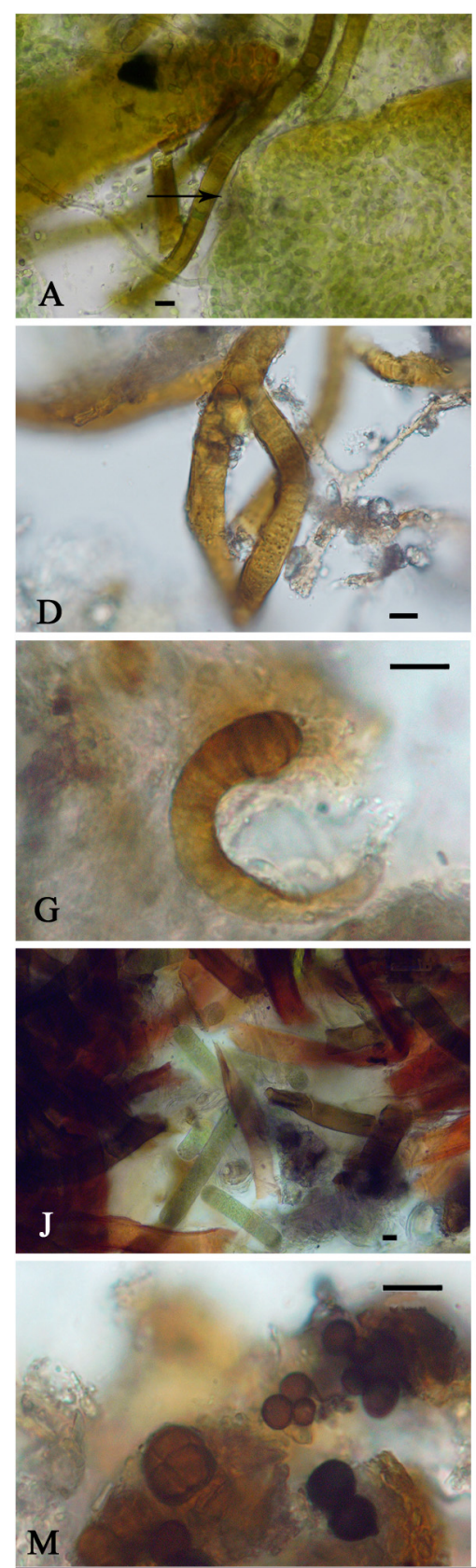
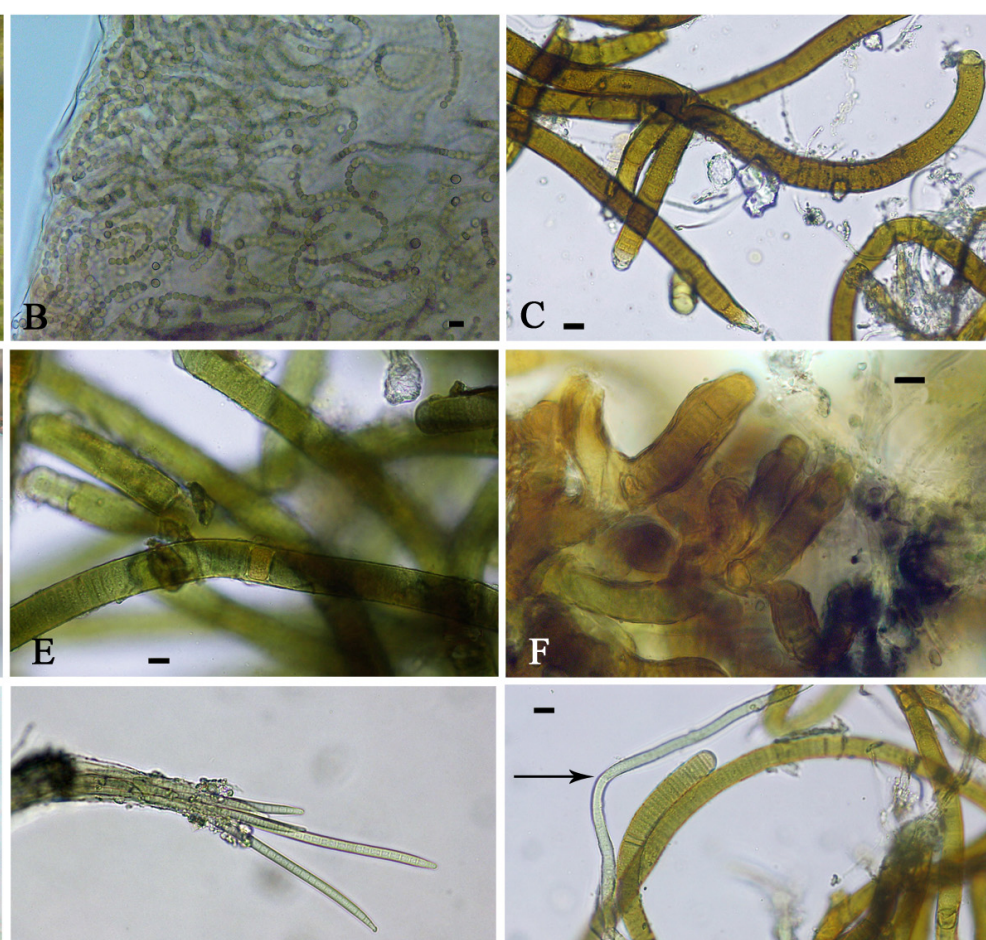

$\mathrm{H}$

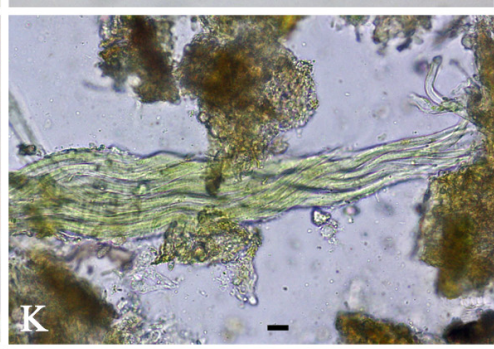

$-\quad \mathrm{I}$
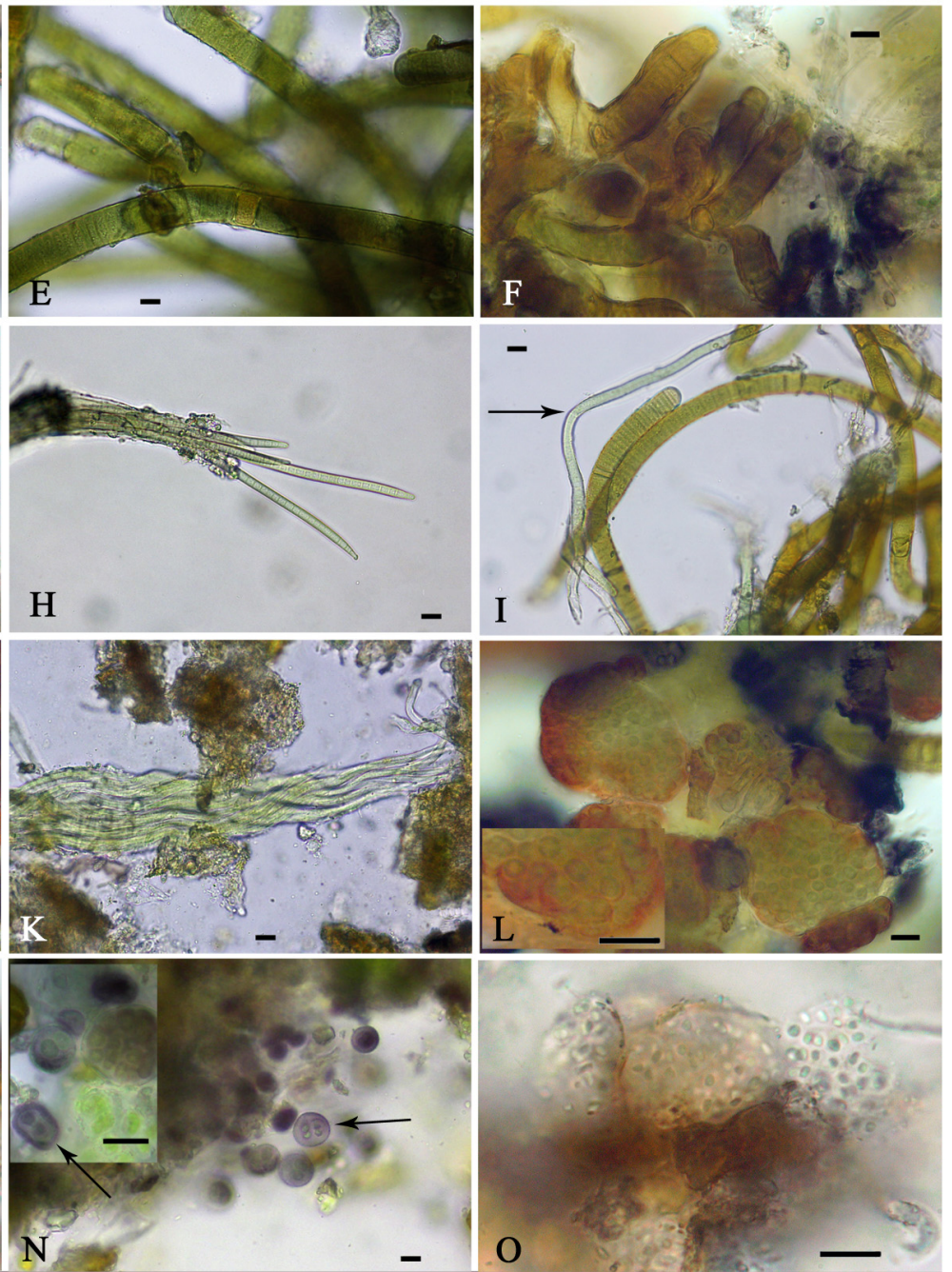

FIGURE 5 | Cyanobacteria observed in field samples: (A) Nostoc commune (black arrow), (B) Nostoc indistinguendum, (C) Scytonema hyalinum, (D) Tolypothrix distorta, (E) Scytonema crispum, (F) Dapisostemon apicaliramis, (G) Calothrix parietina, (H) Microcoleus vaginatus, (I) Chroakolemma opaca (black arrow), (J) Porphyrosiphon notarisii, (K) Symplocastrum flechtnerae, (L) Aphanocapsa sp., (M) Chroococcidiopsis sp.1, (N) Chroococcidiopsis sp.2 (black arrow),

(O) Chlorogloea sp. Scale bar: $10 \mu \mathrm{m}$.

those of this taxon (Figure 3G). The Scytonema hyalinum isolates (Figures 3H,I) also showed typical morphology of the genus, grouping with other sequences of this species in different clusters (clusters VIII and IX) corresponding to two divergent 16S rRNA operons from single strains, as previously found (Yeager et al., 2007; Johansen et al., 2017; Muñoz-Martín et al., 2019).

Regarding non-heterocystous cyanobacteria, unicellular/ colonial cyanobacteria were distributed in the phylogenetic tree among filamentous non-heterocystous cyanobacteria (Figure 4B) as previously found (Komarek et al., 2014). Clusters $a$ and $b$ included representatives of Chroococcidiopsis spp. (Figures 3J,K) together with sequences from this genus from databases (Figure 4B). The other coccoid cyanobacteria, which fitted into the genus Synechococcus (Figure 3L), were distantly placed from the Chroococcidiopsis spp. in the phylogenetic tree, with no matches found in the database (cluster $k$ ). Cluster $c$ 
grouped our isolate identified as Kamptonema sp. (Figure 3M), a new genus derived from the polyphyletic genus Phormidium (Strunecky et al., 2014), with other sequences of this genus (Figure 4B). Typical filamentous cyanobacteria, usually included in taxonomic descriptions from biocrusts, were Microcoleus vaginatus (Figure $\mathbf{3 N}$, cluster $d$ ), Porphyrosiphon notarisii (Figure 30, cluster e), Oculatella atacamensis (Figure 3P, cluster $f$ ), and Leptolyngbya frigida (Figure 3Q, cluster $h$ ). In addition, novel phylotypes and/or morphotypes were found in the studied biocrusts: the 16S rRNA gene sequence from a Schizothrix sp. isolate mapped alone in the tree (Figures 3R,S, cluster $i$ ) since no similar sequences were found in the database (the most similar sequence belonged to an uncultured bacterium with only $96 \%$ similarity). The genera Leptolyngbya and Oculatella were also represented by other sequences with no close relatives (Figures $3 \mathbf{T}-\mathbf{V}, \mathbf{4 B}$ ). Finally, seven of the isolated strains were recently characterized as belonging to a new genus: Chroakolemma (Becerra-Absalon et al., 2018) (Figures 3W,X, cluster j).

\section{Microscopic Observation of Biocrust Field Samples}

The identification of the isolated strains allowed us to better analyze the cyanobacteria observed in the soil samples; however, not all of the isolated strains were observed in these samples which may be due to their presence in relatively small amounts, and some of the cyanobacteria found in the samples could not be isolated. Figure 5 shows representative micrographs of the cyanobacteria from the studied biocrusts, and Table 2 shows the locations of the taxa in the samples. Most of the cyanobacteria found presented envelopes and pigmentation that were characteristic of cyanobacteria found in these extreme environments (Figure 5). Typical heterocystous cyanobacteria from biocrusts, such as $N$. commune, $N$. indistinguendum, S. hyalinum, and $T$. distorta (Figures 5A-D, respectively), were observed at both sampling sites (Table 2). However, other heterocystous forms, such as S. crispum, Dapisostemon apicaliramis and Calothrix parietina (Figures 5E,F,G, respectively), were observed only at the Actopan sampling site (Table 2). Regarding non-heterocystous cyanobacteria, only M. vaginatus (Figure $\mathbf{5 H}$ ) and Chroakolemma sp. (Figure 5I) were observed at both sampling sites, while Porphyrosiphon notarisii (Figure 5J), Symplocastrum flechtnerae (Figure 5K) and Aphanocapsa sp. (Figure 5L) were observed in the Actopan samples. Chroococcidiopsis representatives (Figures $\mathbf{5} \mathbf{M}, \mathbf{N}$ ) and Chlorogloea sp. (Figure 5O) were only found at Atexcac (Table 2).

\section{Molecular Analysis of Microbial Community Composition}

The relative abundance of the dominant phyla of bacteria and plastids from the rRNA gene sequences of the studied biocrusts are displayed in Figure 6. The microbial phototrophs (cyanobacteria and algae) presented similar overall abundances in both samples (52\%). However, this corresponded to a clear dominance of the cyanobacteria at Actopan (45.5\%), while algae was the dominant phototroph community at
TABLE 2 | Cyanobacteria observed in field samples.

\begin{tabular}{lccc}
\hline Taxon & Actopan & Atexcac & Figure \\
\hline Nostoc commune & $X$ & $X$ & Figure 5A \\
Nostoc indistinguendum & $X$ & $X$ & Figure 5B \\
Scytonema hyalinum & $X$ & $X$ & Figure 5C \\
Tolypothrix distorta & $X$ & $X$ & Figure 5D \\
Scytonema crispum & $X$ & & Figure 5E \\
Dapisostemonum apicaliramis & $X$ & & Figure 5F \\
Calothrix parietina & $X$ & & Figure 5G \\
Microcoleus vaginatus & $X$ & $X$ & Figure 5H \\
Chroakolemma sp. & $X$ & $X$ & Figure 5I \\
Porphyrosiphon notarisii & $X$ & & Figure 5J \\
Symplocastrum flechtnerae & $X$ & & Figure 5K \\
Aphanocapsa sp. & $X$ & & Figure 5L \\
Chroococcidiopsis sp. & & $X$ & Figure 5M \\
Chroococcidiopsis sp. & & $X$ & Figure 5N \\
Chlorogloea sp. & & Figure 50 \\
\hline
\end{tabular}

Atexcac (38\%). The rest of the biocrust bacterial rRNA gene sequences were also similar at both sampling sites; Proteobacteria and Bacteroidetes were the most abundant phyla (approximately $14 \%$ in both samples), followed by Actinobacteria (approximately 7\%) and Acidobacteria (approximately $5-6 \%)$. Collectively, algae and all of these described taxa of bacteria accounted for $>90 \%$ of the sequences recovered from these biocrusts.

Regarding cyanobacteria, clear differences were found in their taxonomic composition (Figure 7). The cumulative pie chart shows the distribution of the phylotype counts in which the heterocystous cyanobacteria are by far the most common members at Actopan (69.36\%), while at Atexcac, to reach this percentage, it was necessary to combine the heterocystous cyanobacteria (41.03\%) with the unicellular/colonial cyanobacteria (31.58\%), mostly represented by phylotypes of Chroococcidiopsis. Table 3 shows the taxonomic assignments of the OTUs based largely on comparisons with the sequences and the corresponding phenotypes of the isolated cultures in parallel with the microscopic analysis of the biocrust field samples. We could match sequences from the most abundant taxa (corresponding to OTUs 1-16) thanks to the collection of the isolated strains and/or after Blasting and comparing the results with the recorded morphotypes found at the sampling sites (Table 2). Clear differences in the observed taxa at each sampling site were found (Figure 7). Figure 8 summarizes the data for all the OTUs together in a Venn diagram. Only $28.4 \%$ of the OTUs were found in both soils, while $33.9 \%$ were unique to the Actopan biocrusts and $37.6 \%$ were unique to the Atexcac biocrusts. In addition, differences in the relative abundance of the shared cyanobacteria in the samples were also found. N. commune, S. hyalinum, and Microcoleus sp. were more abundant at Actopan than at Atexcac, and some phylotypes, such as those corresponding to S. crispum, $N$. indistinguendum, $P$. notarisii, and other Oscillatorial, as well as two OTUs corresponding to Nostoc spp. were no present or almost undetectable (less than $1 \%$ of abundance) at Atexcac. 


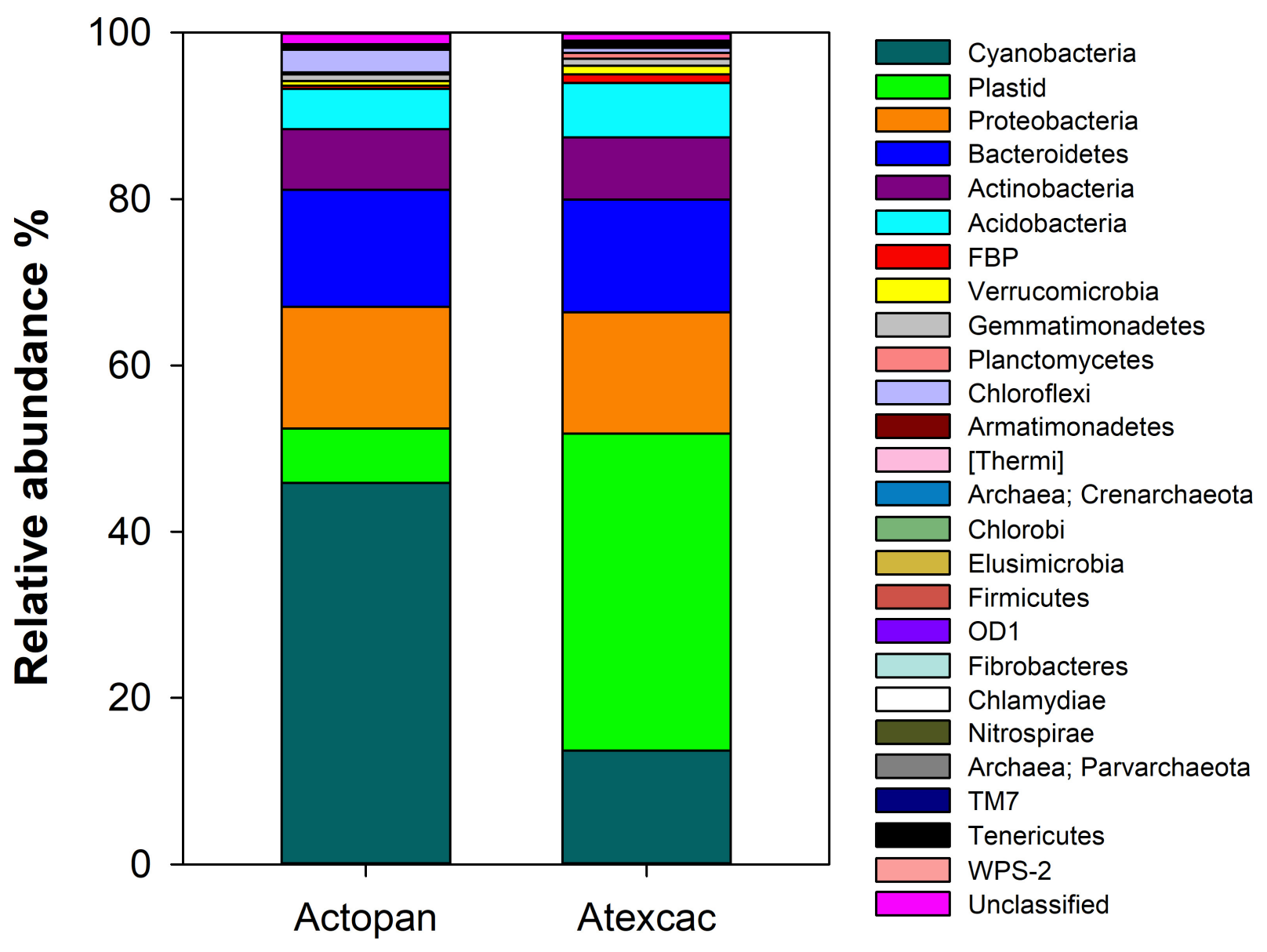

\section{Sampling site}

FIGURE 6 | Taxonomic microbial community composition from the studied biocrusts.

In contrast, $T$. distorta, S. flechtnerae, M. vaginatus Nostoc sp., Oculatella sp., and several OTUs corresponding to the Chroococcidiopsis presented higher abundances at Atexcac than at Actopan, with the percentages of the abundance in the second locality lower than $1 \%$. Interestingly, some of the heterocystous cyanobacteria, although were present in low abundance, were present at only one of the sampling sites: C. parietina, D. apicaliramis, and other Nostocal were present only in Actopan, while Mastigocladopsis sp., Stigonema sp., Macrochaete sp., and Desmonostoc sp. were present only at Atexcac (Figure 7).

\section{Sensitivity of Biocrust Isolated Cultures to Extreme Heat and Desiccation}

Since climatic differences were found at the studied sampling sites, a series of bioassays were carried out to test the sensitivity of the cultured strains to extreme conditions. Table 4 shows (i) the survival of 23 isolated cultures to extreme heat over 1 month, (ii) the subsequent response of the cultures to extreme heat and a year-long desiccation treatment, and (iii) the resilience of the cultures, following these extreme conditions, after the addition of culture medium to the desiccated cells. As expected, the majority of the cultures did not resist extreme heat, showing clear chlorosis within a range of 10-12 days for unicellular/colonial cyanobacteria and 10-20 days for filamentous non-heterocystous forms, except Kamptonema sp. which showed clear chlorosis starting on the fourth day of treatment. Leptolyngbya sp. survived after 25 days at $40^{\circ} \mathrm{C}$ but did not resist additional desiccation. Interestingly, the isolated strain belonging to the new genus Chroakolemma was the only non-heterocystous strain that survived the entire time tested. However, a variety of responses to extreme heat and desiccation were found for the heterocystous cyanobacteria. S. crispum and two strains of $S$. hyalinum and C. parietina survived the entire test period, but $T$. distorta did not survive after 19 days of culture at $40^{\circ} \mathrm{C}$. Both Nostoc strains (N. commune and Nostoc sp.) survived 25 days of extreme heat but showed clear chlorosis after desiccation and extreme heat, and surprisingly recovered the pigmentation after addition of culture medium at room temperature showing resilience following heat and desiccation disturbance (Table 4). 


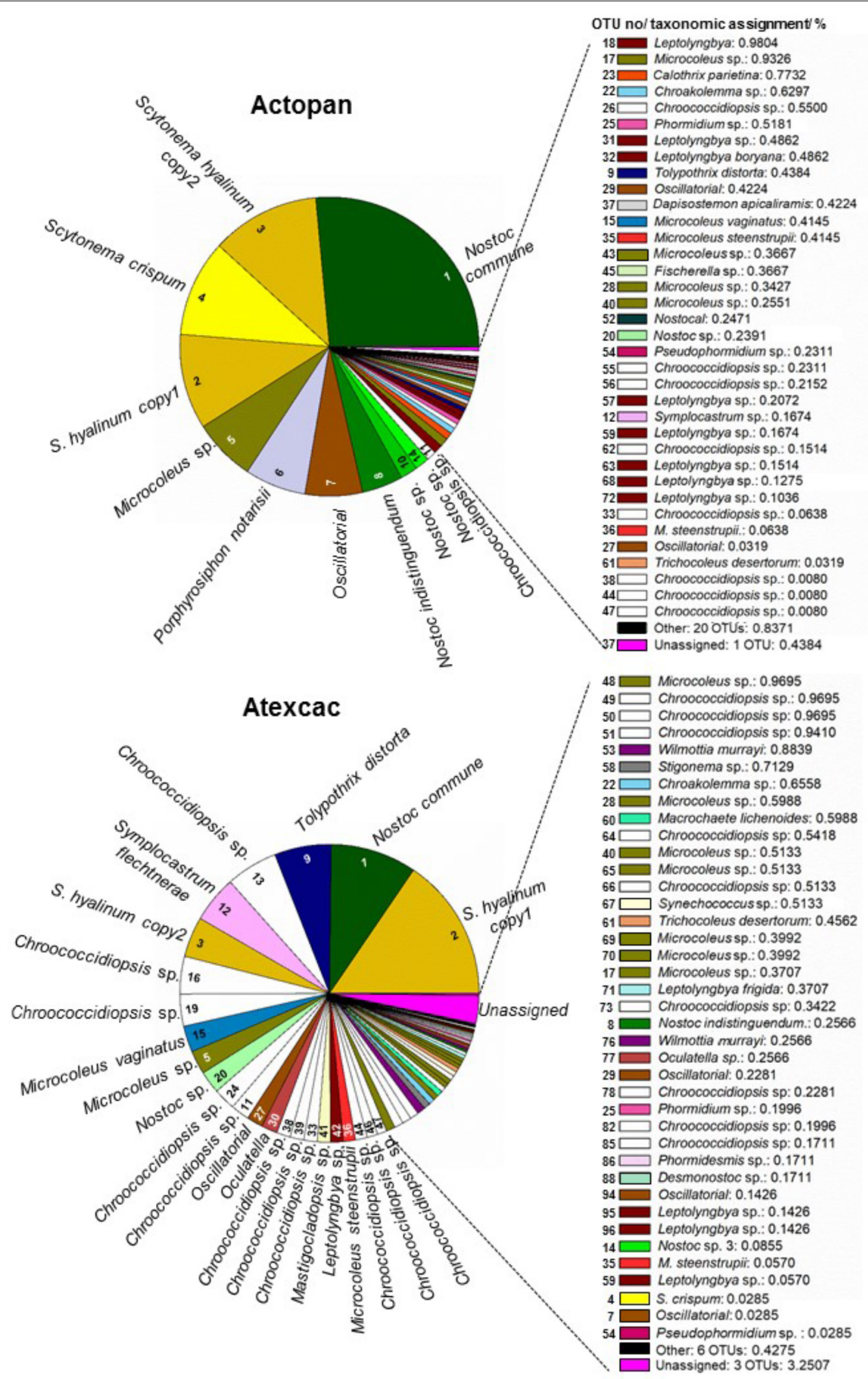

FIGURE 7 | Cyanobacterial community composition from the studied biocrusts. The relative abundance of the OTUs is represented in order of abundance, by a color and the corresponding number (see Table $\mathbf{3}$ for number, taxonomic assignment and colors). 
TABLE 3 | Taxonomic assignments of OTUs.

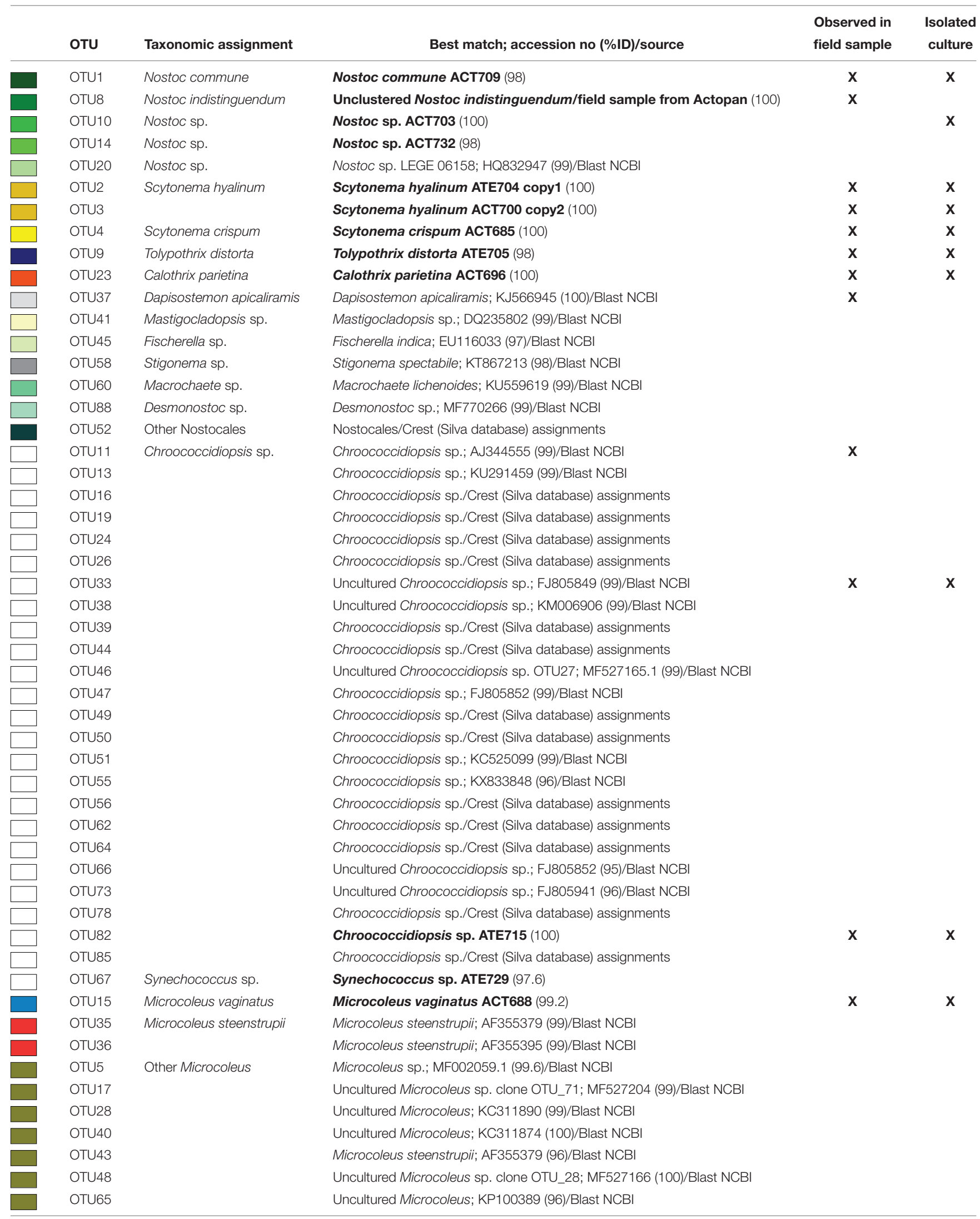


TABLE 3 | Continued

\begin{tabular}{|c|c|c|c|c|}
\hline OTU & Taxonomic assignment & Best match; accession no (\%ID)/source & $\begin{array}{l}\text { Observed in } \\
\text { field sample }\end{array}$ & $\begin{array}{l}\text { Isolated } \\
\text { culture }\end{array}$ \\
\hline OTU69 & & Microcoleus steenstrupii; AJ871982 (95)/Blast NCBI & & \\
\hline OTU70 & & Microcoleus steenstrupii; AJ871979 (96)/Blast NCBI & & \\
\hline OTU6 & Porphyrosiphon notarisii & Porphyrosiphon notarisii (99.2) & $\mathbf{x}$ & $\mathbf{x}$ \\
\hline OTU12 & Symplocastrum flechtnerae & Symplocastrum flechtnerae; KF312349 (99)/Blast NCBI & $\mathbf{x}$ & \\
\hline OTU25 & Phormidium sp. & Phormidium sp.; EU196618 (97) Blast NCBI & & \\
\hline OTU53 & Wilmottia murrayi & Wilmottia murrayi; AY493627 (99.2)/Blast NCBI & & \\
\hline OTU76 & & Wilmottia murrayi; AY493626 (97.6)/Blast NCBI & & \\
\hline OTU54 & Pseudophormidium sp. & Pseudophormidium sp.; KJ939082 (100)/Blast NCBI & & \\
\hline OTU22 & Chroakolemma sp. & Chroakolemma opaca ACT701 (100) & $\mathbf{x}$ & $\mathbf{x}$ \\
\hline OTU30 & Oculatella sp. & Oculatella sp ACT687 (99.2) & $\mathbf{x}$ & $\mathbf{x}$ \\
\hline OTU77 & & Oculatella ucrainica; MG652620 (97)/Blast NCBI & & \\
\hline OTU32 & Leptolyngbya boryana & Leptolyngbya boryana; EF429289 (97.6)/Blast NCBI & & \\
\hline OTU71 & Leptolyngbya frigida & Leptolyngbya frigida; MG641933 (100)/Blast NCBI & $\mathbf{x}$ & $\mathbf{x}$ \\
\hline OTU18 & Other Leptolyngbya & Leptolyngbya sp.; AP017308 (96)/Blast NCBI & & \\
\hline OTU31 & & Leptolyngbya sp. ACT691 (99.6) & & $\mathbf{X}$ \\
\hline OTU42 & & Leptolyngbya sp./QIIME (Greengenes database) assignment & & \\
\hline OTU57 & & Leptolyngbya sp./Crest (Silva database) assignments & & \\
\hline OTU59 & & Leptolyngbya sp./Crest (Silva database) assignments & & \\
\hline OTU63 & & Leptolyngbya sp.; HM018680 (99)/Blast NCBI & & \\
\hline OTU68 & & Leptolyngbya ca. Albertano-Kovacik Green; KC463189 (99)/Blast NCBI & & \\
\hline OTU72 & & Leptolyngbya sp./QIIME (Greengenes database) assignment & & \\
\hline OTU95 & & Leptolyngbya sp./QIIME (Greengenes database) assignment & & \\
\hline OTU96 & & Leptolyngbya sp./QIIME (Greengenes database) assignment & & \\
\hline OTU61 & Trichocoleus desertorum & Trichocoleus desertorum; EU586743 (99)/Blast NCBI & & \\
\hline OTU86 & Phormidesmis sp. & Phormidesmis sp.; KY283068 (99)/Blast NCBI & & \\
\hline OTU7 & Other Oscillatoriales & Oscillatoriales/Crest (Silva database) assignments & & \\
\hline OTU27 & & Uncultured Oscillatoriales cyanobacterium OTU32 (100); MF52717170/Blast NCBI & & \\
\hline OTU29 & & Uncultured Oscillatoriales cyanobacterium OTU40 (99); MF52717178/Blast NCBI & & \\
\hline OTU94 & & Oscillatoriales/Crest (Silva database) assignments & & \\
\hline & Unassigned & OTU21, OTU34, OTU93, OTU98 & & \\
\hline & $<0.1$ & $\begin{array}{l}\text { OTU74, OTU75, OTU79, OTU80, OTU81, OTU83, OTU84, OTU87, OTU89, } \\
\text { OTU90, OTU91, OTU92, OTU97, OTU99, OTU100, OTU101, OTU102, OTU103, } \\
\text { OTU104, OTU105, OTU106, OTU107, OTU108, OTU109 }\end{array}$ & & \\
\hline
\end{tabular}

Isolated strains from this study are in bold. Colors correspond to those in Figure 7.

\section{DISCUSSION}

The distribution of cyanobacterial species and their abundance is of crucial importance for understanding recent and ancient environmental dynamics. However, data about cyanobacterial species distribution are fragmented and strongly biased depending on the work carried out on a certain continent (Büdel et al., 2016). Factors influencing cyanobacterial distribution have been discussed for a long time, and climate and geography have been the main focus of attention. However, recent studies addressed the importance of soil texture on the growth of different cyanobacteria on the soil, in inoculation experiments (Rozenstein et al., 2014; Chamizo et al., 2018); whereby in areas of high fine soil grains content, a high biocrust cover was found (Belnap et al., 2014). The fact that our study area is dominated by fine-textured soils can explain why we found an extensive biocrust cover, similar to those found in previous studies (Williams et al., 2013; Belnap et al., 2014), and a high cyanobacterial diversity.

Molecular investigations through next-generation sequencing culture-independent approaches or by sequencing inserts of clone libraries have shown differences in cyanobacterial diversity depending on the geographical region. Community composition of microbial phototrophs in arid soil biocrusts of the southwestern United States showed that this region was dominated by the bundle-forming, non-heterocystous cyanobacteria Microcoleus vaginatus and Microcoleus steenstrupii; the former mostly dominated in the northern locations, and the second mostly dominated in the southern latitudes (Garcia-Pichel et al., 2013). In Artic biocrusts, cyanobacterial communities were dominated by sequences related to the formgenera Leptolyngbya, Calothrix, Coleofasciculus, Oscillatoria, 
Stigonema, Microcoleus, and Phormidium (Pushkareva et al., 2015). In southern African biocrusts, in addition to typical genera found in biocrusts, such as Microcoleus, Phormidium, Tolypothrix, and Scytonema, sequences corresponding to the genera Leptolyngbya, Pseudanabaena, Oscillatoria, and Schizothrix were also found (Dojani et al., 2014). Analysis of the cyanobacterial diversity of western European biocrusts along a latitudinal gradient demonstrates that all the sites, except Spain, included taxa unique to the surveyed localities, but all the sites were dominated by Leptolyngbya, Phormidium, and a cyanobacterium with no matches in the databases (Williams et al., 2016). Our previous results of biocrusts from a latitudinal and climatic gradient in Spain showed a general dominance of Microcoleus vaginatus and Microcoleus steenstrupii, although differences between the locations were also found, wherein some heterocystous cyanobacteria, such as S. hyalinum, appeared to be dominant in developed biocrusts from the warmest and driest southwest locations (Muñoz-Martín et al., 2019).

The results from the present study revealed clear differences regarding the aforementioned studies. In addition, it is remarkable that although these localities are relatively close and belong to the same desert system (Chihuahuense), the cyanobacterial species composition and abundance are very different between the localities. The taxonomic assignment of the sequences revealed a clear dominance of the heterocystous

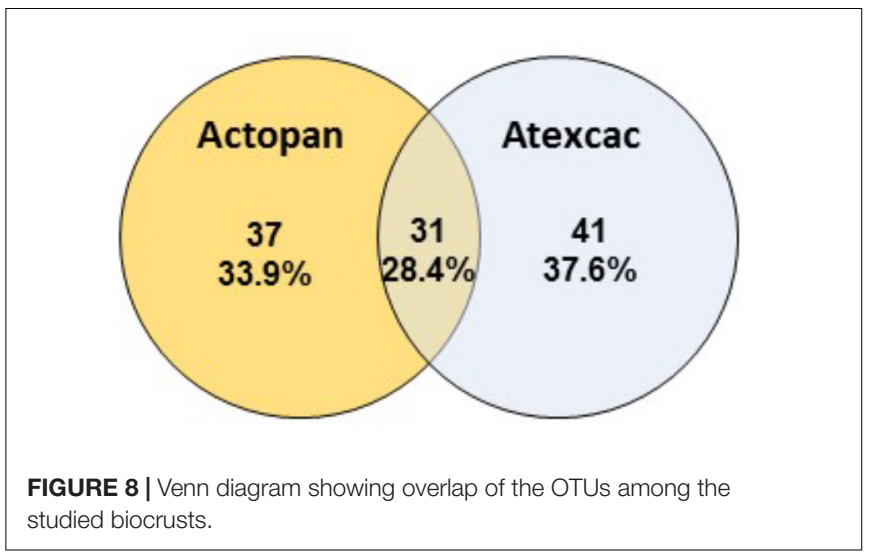

cyanobacteria in Actopan (Hidalgo state), while in Atexcac (Puebla state), although the Nostocales were also abundant, unicellular/colonial cyanobacteria, mostly Chroococcidiopsis spp., represented almost a third of the cyanobacteria present. The Atexcac location harbored greater cyanobacterial diversity than Actopan; in Actopan, the $83 \%$ of the cyanobacterial phylotypes corresponded to 8 OTUs, while in Atexcac, this percentage was distributed among 42 OTUs. To the best of our knowledge, our study is the first to show such great cyanobacterial

TABLE 4 | Survival of cyanobacterial cultures over 25 days at $40^{\circ} \mathrm{C}$, subsequent response of cultures to a year-long desiccation treatment at $40^{\circ} \mathrm{C}$, and later survival following the addition of culture medium to the desiccated cells and maintained to room temperature.

Survival at $40^{\circ} \mathrm{C}$ (days)

Scytonema hyalinum ACT695

Scytonema hyalinum ATE698

Scytonema hyalinum ACT699

Scytonema hyalinum ATE704

Scytonema hyalinum ACT711

Scytonema crispum ACT685

Nostoc sp. ACT703

Nostoc commune ACT709

Tolypothrix distorta ATE705

Calothrix parietina ACT696

Microcoleus vaginatus ACT688

Kamptonema sp. ACT692

Porphyrosiphon notarisii ACT693

Chroakolemma opaca ACT686

Oculatella sp. ACT687

Oculatella atacamensis ATE710

Leptolyngbya frigida ACT684

Leptolyngbya sp. ACT689

Leptolyngbya sp. ACT691

Schizothrix sp. ACT690

Chroococcidiopsis sp. ATE707

Chroococcidiopsis sp. ATE715

Synechococcus sp. ATE729

$\begin{array}{cc}\text { Survival to } & \text { Survival after } \\ \text { desiccation } & \text { rehydration } \\ \text { at } 40^{\circ} \mathrm{C} & \end{array}$

at $40^{\circ} \mathrm{C}$ 
diversity in biocrusts. This high level of diversity suggests a greater ecosystem complexity than previously appreciated. Differences in the cyanobacterial populations in the studied biocrusts compared to other crusts in Mexico were also found. The microscopic analysis of biocrusts from the close Tehuacán Valley, also in the Puebla state, showed that the most common species that were present at the studied sites were Scytonema javanicum, Microcoleus paludosus, and Chroococcidiopsis sp., while Nostoc sp., Schizothrix sp., and Aphanocapsa sp. were found with a lower frequency, and Gloeocapsa sp. was the only rare species of cyanobacteria (Rivera-Aguilar et al., 2006).

Within heterocystous forms, the genera Nostoc and Scytonema were dominant at both studied locations, which may have relevant ecological implications for the nitrogen cycle and other ecosystem services. Nostoc spp. are considered important components of the nitrogen-fixing community in nutrient-poor soils worldwide (Dodds et al., 1995). In addition, macroscopic Nostoc colonies, found usually on the surface (Belnap and Lange, 2003) as well as the Scytonema filaments, undergo intense environmental stresses. These include high daytime temperatures during the summer, low temperatures during the night in the winter, high visible and UV radiation, and frequent hydration-dehydration cycles, which are characteristic of the conditions found at our sampling locations. The aforementioned cyanobacteria have therefore had to develop adaptive structural and physiological mechanisms to live in these places (Hu et al., 2012). One of these mechanisms for the cyanobacteria inhabiting exposed near-surface soils, is to produce photoprotective accessory pigments, such as scytonemins, mycosporine-like amino acids and carotenoids, which increase in content with solar radiation (Bowker et al., 2002), and reduce the amount of UVR damage accrued when cells are desiccated and metabolically inactive or dormant, when temperatures are suboptimal or freezing (Castenholz and GarciaPichel, 2012). Thus, scytonemin-producing cyanobacteria found, play an important role in protecting soil from solar radiation, shading the surrounded community and allowing colonization by other species (Garcia-Pichel and Castenholz, 1991; Singh et al., 2010).

Chroococcidiopsis spp., found in high abundance in Atexcac location, although typically considered hypolithic organisms, are also often found at the soil surface, surviving prolonged desiccation and developing sheaths containing pigments for UV protection (Dillon et al., 2002). In these extreme conditions, usual in this location, adaptation is also related to the secretion of a copious hygroscopic extracellular polymeric substance that enables cyanobacteria to cope with prolonged moisture deficit in hot deserts (Pointing, 2016).

The capacity to adapt to different environmental conditions can be distinct and depends on the attributes of cyanobacteria. Differences in climatic conditions between the studied sites were found and to investigate the possible interrelation between these climate conditions and differences in the cyanobacterial community composition, we analyzed the specific sensitivity of the isolated biocrust cultures to heat and desiccation. The results clearly showed differences between the analyzed strains which might be responsible for generating the differences in composition found. For instance, S. hyalinum and N. commune, which were able to survive to extreme conditions in the bioassays, presented higher abundances at the Actopan location, where a maximum temperature of $47^{\circ} \mathrm{C}$ was reached, than at Atexcac, where the maximum temperature was just $36^{\circ} \mathrm{C}$. Much of the success of Nostoc in dryland habitats is related to its ability to remain desiccated for months, years, or even several decades (Hu et al., 2012) and to fully recover its metabolic activity within hours to days after rehydration with liquid water (Dodds et al., 1995). In fact, it has been found that $N$. commune from terrestrial habitats in China recovered after a drought period of 2 years, with reactivation of respiration, photosynthesis, and nitrogen fixation (Scherer et al., 1984). Evidence has shown that the development of specialized cells, such as akinetes (spore-like) which are cell survival stages that are known only in heterocystous cyanobacteria, leads to higher tolerance to dryness than in other stages ( $\mathrm{Hu}$ et al., 2012). Therefore, the development of akinetes in Nostoc cultures can explain the observed survival after a year of desiccation at $40^{\circ} \mathrm{C}$. Additionally, desiccation provides some protection to high temperature for biocrust cyanobacteria (Lan et al., 2014) which could also explain the resilience to this disturbance.

Understanding differences in the cyanobacterial diversity living in dryland areas remains essential since these biota play a critical role in ecosystem functioning. In addition to the geographic patterns of distribution discussed above, the heterogeneity of microenvironments or microclimatic gradients can also influence cyanobacterial diversity. Therefore, in our study, the nature of the cyanobacterial community structure seems to depend on these specific characteristics rather than the geographic location of the study sites. For a long time, some cyanobacteria have been reported as unique and endemic to specific sites, such as hot or polar environments (e.g., Castenholz, 1996; Taton et al., 2003). The question of endemism of cyanobacteria remains unsettled, and currently accepted theories about microbial biogeography assume that most microorganisms are cosmopolitan and ubiquitous (Fenchel and Finlay, 2004; Foissner, 2008). The paradigm "everything is everywhere, the environment selects" (Beijerinck, 1913; Becking, 1934) has been a starting point for studies of prokaryotic biodiversity and their biogeographical patterns (De Wit and Bouvier, 2006 and references therein). However, recent studies dispute the idea that 'everything is everywhere', and the claim that 'the environment selects' implies that different contemporary environments maintain distinctive microbial assemblages (Martiny et al., 2006). Komárek (2015) found specific endemic Antarctic cyanobacterial units, inconsistent with the cosmopolitan hypothesis. Furthermore, several authors encourage the theory of cyanobacterial endemism, reporting unique distributions of some taxa. Sherwood $(2004,2007)$ and Sherwood et al. (2015) characterized Hawaiian freshwater and terrestrial cyanobacteria, revealing high diversity and numerous cyanobacterial species that are believed to be endemic to 
the Hawaiian Islands. Kastovsky et al. (2016) described two new cyanobacterial species, presumably endemic taxa of the Chimantá Massif, Venezuela. Analysis of the cyanobacteria from hot water springs of the North-Western Himalayas harbored endemic cyanobacterial species (Singh et al., 2018). Lastly, in comparing the cyanobacteria within the biocrusts of the Arctic, Antarctic, and European Alpine sites, the discovery of a new Oculatella species, through the polyphasic approach, enhanced arguments for cold-assigned cyanobacterial endemism (Jung et al., 2018). The results from the present study support this view, whereby phylogenetic analysis revealed novel phylotypes not previously found with some of them present in high abundances (see, e.g., OTU 7, and those taxa corresponding mainly to Chroococcidiopsis spp.). Mexico contains a great diversity of topography and climate because of its complex geology, with the existence of a fair number of regions that behave as true ecological islands and peninsulas; these climatic and topographical attributes have led to the recognition of a large proportion of endemic genera, most of them related to the degree of climatic aridity (Rzedowski, 1991; Rodrigues et al., 2004) which is a trait that can be reflected in the cyanobacteria present as well. In fact, although the two sampling sites belong to the Chihuahuan Desert, they are separated by the TransMexican Volcanic Belt, a forested cordillera lacking biocrusts that acts as a high elevation barrier to the dispersal of plant and animal species. Thus, our sites harbored cosmopolitan cyanobacteria, such as the typical taxa generally found in

\section{REFERENCES}

Alcocer, D., Escolero, A., and Marín, L. E. (2004). "Problemática del agua de la Cuenca Oriental, estados de Puebla, Veracruz y Tlaxcala," in El Agua en México Vista Desde la Academia, ed. B. M. Jiménez (Mexico: Academia Mexicana de Ciencias), 57-77.

Altschul, S. F., Gish, W., Miller, W., Myers, E. W., and Lipman, D. J. (1990). Basic local alignment search tool. J. Mol. Biol. 215, 403-410.

Barger, N. N., Weber, B., Garcia-Pichel, F., Zaady, E., and Belnap, J. (2016). "Patterns and controls on nitrogen cycling of biological soil crusts," in Biological Soil Crusts: an Organizing Principle in Drylands, eds B. Weber, B. Büdel, and J. Belnap (Berlin: Springer), 257-285.

Becerra-Absalon, I., Johansen, J. R., Munoz-Martin, M. A., and Montejano, G. (2018). Chroakolemma gen. nov. (Leptolyngbyaceae, Cyanobacteria) from soil biocrusts in the semi-desert central region of Mexico. Phytotaxa 367, 201-218. doi: 10.11646/phytotaxa.367.3.1

Becking, L. B. (1934). Geobiologie of Inleiding Tot De Milieukunde. Den Haag: WP Van Stockum \& Zoon.

Beijerinck, M. W. (1913). "De infusies en de ontdekking der backteriën," in Jaarboek Van de Koninklijke Akademie, ed. V. Wetenschappen (Amsterdam: Müller).

Belnap, J., and Lange, O. L. (2003). Biological Soil Crusts: Structure, Function, and Management. Berlin: Springer.

Belnap, J., Miller, D. M., Bedford, D. R., and Phillips, S. L. (2014). Pedological and geological relationships with soil lichen and moss distribution in the eastern Mojave Desert, CA, USA. J. Arid Environ. 106, 45-57. doi: 10.1016/j.jaridenv. 2014.02.007

Bowker, M. A., Belnap, J., Büdel, B., Sannier, C., Pietrasiak, N., Eldridge, D. J., et al. (2016). "Controls on distribution patterns of biological soil crusts at micro-to global scales," in Biological Soil Crusts: An Organizing Principle in Drylands, eds B. Weber, B. Büdel, and J. Belnap (Berlin: Springer), 173-197. biocrusts (e.g., N. commune, S. hyalinum, T. distorta) but also presented novel biocrust-associated phylotypes that could be endemic. Further analysis of the biogeographical relationships and extending the sampling sites comprehensively throughout the world will determine if the current putative endemic cyanobacteria reflect the gaps in our knowledge of cyanobacterial diversity or if there is true endemism.

\section{AUTHOR CONTRIBUTIONS}

IB-A and PM designed the study. IB-A collected the biocrust samples and performed laboratory work. IB-A and GM performed the microscopic study. IB-A, MM-M, and PM performed the bioinformatics analysis of sequence data. The first draft of this manuscript was written by PM and all co-authors contributed to improve it.

\section{FUNDING}

This study was supported by grants from the Spanish Government and European Regional Funds (CGL2013-44870-R and CGL2017-86258-R) and by a grant from the Universidad Autónoma de Madrid and Banco de Santander (CEAL-AL/2017-10). IB-A acknowledges support from CONACyT-Mexico postdoctoral fellowship at Universidad Autónoma de Madrid.

Bowker, M. A., Reed, S. C., Belnap, J., and Phillips, S. L. (2002). Temporal variation in community composition, pigmentation, and F-v/F-m of desert cyanobacterial soil crusts. Microb. Ecol. 43, 13-25. doi: 10.1007/s00248-001-1013-9

Büdel, B., Darienko, T., Deutschewitz, K., Dojani, S., Friedl, T., Mohr, K. I., et al. (2009). Southern African biological soil crusts are ubiquitous and highly diverse in drylands, being restricted by rainfall frequency. Microb. Ecol. 57, 229-247. doi: 10.1007/s00248-008-9449-9

Büdel, B., Duliæ, T., Darienko, T., Rybalka, N., and Friedl, T. (2016). "Cyanobacteria and Algae of Biological Soil Crusts," in Biological Soil Crusts: An Organizing Principle in Drylands, eds B. Weber, B. Büdel, and J. Belnap (Cham: Springer International Publishing), 55-80.

Caporaso, J. G., Kuczynski, J., Stombaugh, J., Bittinger, K., Bushman, F. D., Costello, E. K., et al. (2010). QIIME allows analysis of high-throughput community sequencing data. Nat. Methods 7, 335-336. doi: 10.1038/nmeth.f.303

Caporaso, J. G., Lauber, C. L., Walters, W. A., Berg-Lyons, D., Lozupone, C. A., Turnbaugh, P. J., et al. (2011). Global patterns of 16S rRNA diversity at a depth of millions of sequences per sample. Proc. Natl. Acad. Sci. 108(Suppl. 1), 4516-4522. doi: 10.1073/pnas.1000080107

Castenholz, R. W. (1996). Endemism and biodiversity of thermophilic cyanobacteria. Nova Hedwigia Beiheft 112, 33-48.

Castenholz, R. W., and Garcia-Pichel, F. (2012). "Cyanobacterial responses to UV radiation," in Ecology of Cyanobacteria II, ed. B. Whitton (Berlin: Springer), 481-499.

Castillo-Monroy, A. P., Bowker, M. A., Maestre, F. T., Rodríguez-Echeverría, S., Martinez, I., Barraza-Zepeda, C. E., et al. (2011). Relationships between biological soil crusts, bacterial diversity and abundance, and ecosystem functioning: Insights from a semi-arid Mediterranean environment. J. Vegetat. Sci. 22, 165-174.

Chamizo, S., Mugnai, G., Rossi, F. R., Certini, G., and De Philippis, R. (2018). Cyanobacteria inoculation improves soil stability and fertility on different textured soils: gaining insights for applicability in soil restoration. Front. Environ. Sci. 6:49. doi: 10.3389/fenvs.2018.00049 
De Wit, R., and Bouvier, T. (2006). 'Everything is everywhere, but, the environment selects'; what did baas becking and Beijerinck really say? Environ. Microbiol. 8, $755-758$.

Dillon, J. G., Tatsumi, C. M., Tandingan, P. G., and Castenholz, R. W. (2002). Effect of environmental factors on the synthesis of scytonemin, a UV-screening pigment, in a cyanobacterium (Chroococcidiopsis sp.). Arch. Microbiol. 177, 322-331. doi: 10.1007/s00203-001-0395-x

Dodds, W. K., Gudder, D. A., and Mollenhauer, D. (1995). The ecology of Nostoc. J. Phycol. 31, 2-18. doi: 10.1111/j.0022-3646.1995.00002.x

Dojani, S., Kauff, F., Weber, B., and Budel, B. (2014). Genotypic and phenotypic diversity of cyanobacteria in biological soil crusts of the Succulent Karoo and Nama Karoo of southern Africa. Microb. Ecol. 67, 286-301. doi: 10.1007/ s00248-013-0301-5

Edgar, R. C. (2010). Search and clustering orders of magnitude faster than BLAST. Bioinformatics 26, 2460-2461. doi: 10.1093/bioinformatics/btq461

Edgar, R. C. (2013). UPARSE: highly accurate OTU sequences from microbial amplicon reads. Nat. Methods 10, 996-998. doi: 10.1038/nmeth.2604

Felsenstein, J. (1985). Confidence limits on phylogenies: an approach using the bootstrap. Evolution 39, 783-791. doi: 10.1111/j.1558-5646.1985.tb00420.x

Fenchel, T., and Finlay, B. J. (2004). The ubiquity of small species: patterns of local and global diversity. Bioscience 54, 777-784. doi: 10.1073/pnas.1012678108

Foissner, W. (2008). Protist diversity and distribution: some basic considerations. Biodivers. Conserv. 17, 235-242. doi: 10.1007/s10531-007-9248-5

Garcia-Pichel, F., Felde, V. J. M. N. L., Drahorad, S. L., and Weber, B. (2016). "Microstructure and weathering processes within biological soil crusts," in Biological Soil Crusts: An Organizing Principle in Drylands, eds B. Weber, B. Büdel, and J. Belnap (Cham: Springer), 237-255.

Garcia-Pichel, F., Loza, V., Marusenko, Y., Mateo, P., and Potrafka, R. M. (2013). Temperature drives the continental-scale distribution of key microbes in topsoil communities. Science 340, 1574-1577. doi: 10.1126/science.1236404

Garcia-Pichel, F., and Wojciechowski, M. F. (2009). The evolution of a capacity to build supra-cellular ropes enabled filamentous cyanobacteria to colonize highly erodible substrates. PLoS One 4:e7801. doi: 10.1371/journal.pone.0007801

Garcia-Pichel, F. (2002). "Desert environments: biological soil crusts," in Encyclopedia of Environmental Microbiology, ed. G. Bitton (New York, NY: John Wiley), 1019-1023.

Garcia-Pichel, F., and Castenholz, R. W. (1991). Characterization and biological implications of scytonemin, a cyanobacterial sheath pigment1. J. Phycol. 27, 395-409.

Gkelis, S., Rajaniemi, P., Vardaka, E., Moustaka-Gouni, M., Lanaras, T., and Sivonen, K. (2005). Limnothrix redekei (van goor) meffert (cyanobacteria) strains from Lake Kastoria, Greece form a separate phylogenetic group. Microb. Ecol. 49, 176-182.

$\mathrm{Hu}, \mathrm{C} ., \mathrm{Gao}, \mathrm{K}$. , and Whitton, B. A. (2012). "Semi-arid regions and deserts," in Ecology of Cyanobacteria II, ed. B. Whitton (Dordrecht: Springer), 345-369.

Johansen, J. R., Mareš, J., Pietrasiak, N., Bohunická, M., Zima, J. Jr., Štenclová, L., et al. (2017). Highly divergent $16 \mathrm{~S}$ rRNA sequences in ribosomal operons of Scytonema hyalinum (Cyanobacteria). PLoS One 12:e0186393. doi: 10.1371/ journal.pone.0186393

Jung, P., Briegel-Williams, L., Schermer, M., and Büdel, B. (2018). Strong in combination: polyphasic approach enhances arguments for cold-assigned cyanobacterial endemism. MicrobiologyOpen doi: 10.1002/mbo3.729

Kastovsky, J., Vesela, J., Bohunicka, M., Fucikova, K., Štenclova, L., and BrewerCarias, C. (2016). New and unusual species of cyanobacteria, diatoms and green algae, with a description of a new genus Ekerewekia gen. nov.(Chlorophyta) from the table mountain Churí-tepui, Chimantá Massif (Venezuela). Phytotaxa 247, 153-180.

Komárek, J. (2013). “Cyanoprokaryota: 3rd Part: Heterocystous Genera," in Süßwasserflora Von Mitteleuropa, Bd, eds B. Büdel, G. Gärtner, L. Krienitz, and M. Schagerl (Berlin: Springer Spektrum).

Komárek, J. (2015). About endemism of cyanobacteria in freshwater habitats of maritime Antarctica. Algol. Stud. 148, 15-32.

Komárek, J., and Anagnostidis, K. (1999). "Cyanoprokaryota. 1. Teil: Chroococcales," in Sußwasserflora Von Mitteleuropa, Bd, eds H. Ettl, G. Gartner, G. Heynig, and D. Mollenhauer (Jena: Gustav Fischer).

Komárek, J., and Anagnostidis, K. (2005). "Cyanoprocaryota 2. Teil: Oscillatoriales," in Sußwasserflora Von mitteleuropa 19/2, (Heidelberg: Elsevier Spektrum), 759.
Komarek, J., Kastovsky, J., Mares, J., and Johansen, J. R. (2014). Taxonomic classification of cyanoprokaryotes (Cyanobacterial genera) 2014, using a polyphasic approach. Preslia 86, 295-335.

Kumar, S., Stecher, G., and Tamura, K. (2016). MEGA7: molecular evolutionary genetics analysis version 7.0 for bigger datasets. Mol. Biol. Evol. 33, 1870-1874. doi: 10.1093/molbev/msw054

Lan, S., Wu, L., Zhang, D., and Hu, C. (2014). Desiccation provides photosynthetic protection for crust cyanobacteria Microcoleus vaginatus from high temperature. Physiol. Plant. 152, 345-354. doi: 10.1111/ppl.12176

Lange, O. L., and Belnap, J. (2016). "How biological soil crusts became recognized as a functional unit: A selective history," in Biological Soil Crusts: An Organizing Principle in Drylands, eds B. Weber, B. Büdel, and J. Belnap (Berlin: Springer), 15-33.

Lanzen, A., Jorgensen, S. L., Huson, D. H., Gorfer, M., Grindhaug, S. H., Jonassen, I., et al. (2012). CREST-classification resources for environmental sequence tags. PLoS One 7:e49334. doi: 10.1371/journal.pone.0049334

Lepère, C., Wilmotte, A., and Meyer, B. (2000). Molecular diversity of Microcystis strains (Cyanophyceae, Chroococcales) based on 16S rDNA sequences. Systemat. Geogr. Plants 70, 275-283.

Loza, V., Perona, E., and Mateo, P. (2013). Molecular fingerprinting of cyanobacteria from river biofilms as a water quality monitoring tool. Appl. Environ. Microbiol. 79, 1459-1472. doi: 10.1128/AEM.03351-12

Martiny, J. B. H., Bohannan, B. J., Brown, J. H., Colwell, R. K., Fuhrman, J. A., Green, J. L., et al. (2006). Microbial biogeography: putting microorganisms on the map. Nat. Rev. Microbiol. 4:102.

Mateo, P., Perona, E., Berrendero, E., Leganés, F., Martín, M., and Golubiæ, S. (2011). Life cycle as a stable trait in the evaluation of diversity of Nostoc from biofilms in rivers. FEMS Microbiol. Ecol. 76, 185-198. doi: 10.1111/j.1574-6941. 2010.01040.x

McDonald, D., Price, M., Goodrich, J., Nawrocki, E., DeSantis, T., Probst, A., et al. (2011). An improved greengenes taxonomy with explicit ranks for ecological and evolutionary analyses of bacteria and archaea. ISME J. 6:610e618. doi: 10.1038/ismej.2011.139

Montaño, A., and Monroy, A. (2000). Conservación ecológica de suelos en zonas áridas y semiáridas en México. Ciencia Desarrollo 154, 26-37.

Müller, J., Müller, K., Neinhuis, C., and Quandt, D. (2010). PhyDe.-Phylogenetic Data Editor: version 0.997. Available at www.Phyde.de

Muñoz-Martín, M. Á, Becerra-Absalón, I., Perona, E., Fernández-Valbuena, L., Garcia-Pichel, F., and Mateo, P. (2019). Cyanobacterial biocrust diversity in Mediterranean ecosystems along a latitudinal and climatic gradient. New Phytol. 221, 123-141. doi: 10.1111/nph.15355

Navas-Molina, J. A., Peralta-Sanchez, J. M., Gonzalez, A., McMurdie, P. J., Vazquez-Baeza, Y., Xu, Z., et al. (2013). Advancing our understanding of the human microbiome using QIIME. Methods Enzymol. 531, 371-444. doi: 10. 1016/B978-0-12-407863-5.00019-8

Pointing, S. B. (2016). "Hypolithic communities," in Biological Soil Crusts: An organizing Principle in Drylands, eds B. Weber, B. Büdel, and J. Belnap (Cham: Springer), 199-213.

Pushkareva, E., Pessi, I. S., Wilmotte, A., and Elster, J. (2015). Cyanobacterial community composition in Arctic soil crusts at different stages of development. FEMS Microbiol. Ecol. 91:fiv143. doi: 10.1093/femsec/ fiv143

Pylro, V. S., Roesch, L. F., Morais, D. K., Clark, I. M., Hirsch, P. R., and Totola, M. R. (2014). Data analysis for 16 S microbial profiling from different benchtop sequencing platforms. J. Microbiol. Methods 107, 30-37. doi: 10.1016/j.mimet. 2014.08.018

Rippka, R., Deruelles, J., Waterbury, J. B., Herdman, M., and Stanier, R. Y. (1979). Generic assignments, strain histories and properties of pure cultures of cyanobacteria. Microbiology 111, 1-61. doi: 10.1099/00221287-111-1-1

Rivera-Aguilar, V., Manuell-Cacheux, I., and Gordínez-Álvarez, H. (2004). Las costras biológicas del suelo y las zonas áridas. Ciencias 75, 24-27.

Rivera-Aguilar, V., Montejano, G., Rodríguez-Zaragoza, S., and Durán-Díaz, A. (2006). Distribution and composition of cyanobacteria, mosses and lichens of the biological soil crusts of the Tehuacán Valley, Puebla, México. J. Arid Environ. 67, 208-225.

Rodrigues, A. S., Andelman, S. J., Bakarr, M. I., Boitani, L., Brooks, T. M., Cowling, R. M., et al. (2004). Effectiveness of the global protected area network in representing species diversity. Nature 428:640. 
Rozenstein, O., Zaady, E., Katra, I., Karnieli, A., Adamowski, J., and Yizhaq, H. (2014). The effect of sand grain size on the development of cyanobacterial biocrusts. Aeolian Res. 15, 217-226.

Rzedowski, J. (1978). Vegetación de México. Mexico, DF: Limusa.

Rzedowski, J. (1991). El endemismo en la flora fanerogámica mexicana: una apreciación analítica preliminar. Acta Bot. Mexicana 15, 47-64.

Rzedowski, J. (2006). Vegetación de México. 1ra. Edición. México: digital, Comisión Nacional para el Conocimiento y Uso de la Biodiversidad, 504.

Scherer, S., Ernst, A., Chen, T.-W., and Böger, P. (1984). Rewetting of droughtresistant blue-green algae: time course of water uptake and reappearance of respiration, photosynthesis, and nitrogen fixation. Oecologia 62, 418-423. doi: $10.1007 / B F 00384277$

Sherwood, A. R. (2004). "Bibliographic checklist of the non-marine algae of the Hawaiian Islands," in Bishop Museum Occassional Papers Series, eds E. F. Stoermer, G. Emmert, M. L. Julius, and C. L. Schelske (Princeton, NJ: Citeseer).

Sherwood, A. R. (2007). Where are we now regarding Hawaiian stream algal systematics? (A suspiciously cosmopolitan flora). Bish. Mus. Bull. Cult. Envir. Stud. 3, 195-206.

Sherwood, A. R., Carlile, A. L., Vaccarino, M. A., and Johansen, J. R. (2015). Characterization of Hawaiian freshwater and terrestrial cyanobacteria reveals high diversity and numerous putative endemics. Phycol. Res. 63, 85-92. doi: 10.1111/pre. 12080

Singh, S. P., Kumari, S., Rastogi, R. P., Singh, K. L., and Sinha, R. P. (2010). Photoprotective and biotechnological potentials of cyanobacterial sheath pigment, scytonemin. Afr. J. Biotechnol. 9, 580-588.

Singh, Y., Gulati, A., Singh, D. P., and Khattar, J. I. S. (2018). Cyanobacterial community structure in hot water springs of Indian North-Western Himalayas: a morphological, molecular and ecological approach. Algal Res. 29, 179-192. doi: 10.1016/j.algal.2017.11.023

Strunecky, O., Komarek, J., and Smarda, J. (2014). Kamptonema (Microcoleaceae, Cyanobacteria), a new genus derived from the polyphyletic Phormidium on the basis of combined molecular and cytomorphological markers. Preslia 86, 193-208.

Taton, A., Grubisic, S., Brambilla, E., De Wit, R., and Wilmotte, A. (2003). Cyanobacterial diversity in natural and artificial microbial mats of Lake Fryxell (McMurdo dry valleys, Antarctica): a morphological and molecular approach. Appl. Environ. Microbiol. 69, 5157-5169. doi: 10.1128/aem.69.9.5157-5169. 2003
Williams, A. J., Buck, B. J., Soukup, D. A., and Merkler, D. J. (2013). Geomorphic controls on biological soil crust distribution: a conceptual model from the Mojave Desert (USA). Geomorphology 195, 99-109. doi: 10.1016/j.geomorph. 2013.04.031

Williams, L., Loewen-Schneider, K., Maier, S., and Budel, B. (2016). Cyanobacterial diversity of western European biological soil crusts along a latitudinal gradient. FEMS Microbiol. Ecol. 92:fiw157. doi: 10.1093/femsec/ fiw157

Wilmotte, A., Van der Auwera, G., and De Wachter, R. (1993). Structure of the $16 \mathrm{~S}$ ribosomal RNA of the thermophilic cyanobacterium Chlorogloeopsis HTF ('Mastigocladus laminosus HTF') strain PCC7518, and phylogenetic analysis. FEBS Lett. 317, 96-100.

Yeager, C. M., Kornosky, J. L., Morgan, R. E., Cain, E. C., Garcia-Pichel, F., Housman, D. C., et al. (2007). Three distinct clades of cultured heterocystous cyanobacteria constitute the dominant N2-fixing members of biological soil crusts of the Colorado Plateau. USA. FEMS Microbiol. Ecol. 60, 85-97. doi: 10.1111/j.1574-6941.2006.00265.x

Yilmaz, P., Parfrey, L. W., Yarza, P., Gerken, J., Pruesse, E., Quast, C., et al. (2014). The SILVA and "all-species living tree project (LTP)" taxonomic frameworks. Nucleic Acids Res. 42, D643-D648. doi: 10.1093/nar/ gkt1209

Zhou, X., Smith, H., Silva, A. G., Belnap, J., and Garcia-Pichel, F. (2016). Differential responses of dinitrogen fixation, diazotrophic cyanobacteria and ammonia oxidation reveal a potential warming-induced imbalance of the N-cycle in biological soil crusts. PLoS One 11:e0164932. doi: 10.1371/journal. pone.0164932

Conflict of Interest Statement: The authors declare that the research was conducted in the absence of any commercial or financial relationships that could be construed as a potential conflict of interest.

Copyright (c) 2019 Becerra-Absalón, Muñoz-Martín, Montejano and Mateo. This is an open-access article distributed under the terms of the Creative Commons Attribution License (CC BY). The use, distribution or reproduction in other forums is permitted, provided the original author(s) and the copyright owner(s) are credited and that the original publication in this journal is cited, in accordance with accepted academic practice. No use, distribution or reproduction is permitted which does not comply with these terms. 